\title{
Enfermedad de Chagas
}

\section{Biología molecular}

\section{Respuesta celular (CD8 ${ }^{+}$) antígeno específica frente a la infección por Trypanosoma cruzi}

Adriana Egui ${ }^{1}$, M. Carmen Thomas ${ }^{1}$, María Morell ${ }^{1}$, Concepción Marañón1, Bartolomé Carrilero², Manuel Segovia², Joaquín Gascón ${ }^{3}$, Concepción Puerta $^{4}$, Manuel Carlos López ${ }^{1}$

1 Instituto de Parasitología y Biomedicina López Neyra, Consejo Superior de Investigaciones Científicas, Granada, España

2 Hospital Virgen de la Arrixaca, Murcia, España

3 Centro de Investigación en Salud Internacional de Barcelona, Hospital Clinic de Barcelona, España

4 Departamento de Microbiología, Pontificia Universidad Javeriana, Bogotá, D.C., Colombia

Introducción. Trypanosoma cruzi es el agente causante de la enfermedad de Chagas. Esta se inicia con una fase aguda que, en ausencia de tratamiento, deriva en una fase crónica asintomática caracterizada por la existencia de un equilibrio entre la respuesta inmune del huésped y la proliferación del parásito. Este equilibrio es sumamente frágil permitiendo la proliferación parasitaria en los tejidos y generando las patologías graves características de la fase crónica sintomática. A pesar de los avances realizados para establecer la dinámica de la respuesta inmune antiparasitaria durante la fase crónica de la enfermedad, este sigue siendo un importante objetivo por resolver.

En el presente trabajo se identifican y caracterizan epítopos $\mathrm{T} \mathrm{CD}^{+}$restringidos a HLA-A*0201 contenidos en las proteínas PFR2 y PFR3 de $T$. cruzi.

Materiales y métodos. La expresión y localización de las proteínas PFR2/PFR3 se determina mediante Western blot e inmunofluorescencia indirecta. La afinidad de unión de los péptidos HLA-A*0201 contenidos en PFR2/PFR3 es evaluada sobre células T2. El reconocimiento de los péptidos por células mononucleares de sangre periférica de pacientes de Chagas se realiza mediante detección de Granzima B (ELISPOT) y de diferentes citocinas (Multiplex). El reconocimiento restringido a células T-CD8+ se demostró estimulando con células K562A2 cargadas de péptido.

Resultados. En modelos de inmunización en ratón y en células mononucleares de sangre periférica de pacientes de Chagas se observó el reconocimiento de 6 epítopos T-CD8 ${ }^{+}$(3/PFR2 y 3/PFR3). Cinco de estos péptidos inducen la presencia de linfocitos $T$ citotóxicos antígeno-específicos secretores de Granzima B, únicamente en los pacientes en fase indeterminada de la enfermedad. En pacientes en fase crónica cardiaca sólo es detectada la secreción de citocinas Tc1 (IFN $\gamma$ y TNFa) e IL6.

Conclusiones. Las proteínas PFR2 y PFR3 contienen epítopos $\mathrm{T} \mathrm{CD}^{+}$inmunodominantes procesados y presentados durante la enfermedad de Chagas, con un reconocimiento funcionalmente diferencial dependiendo del estadio de la enfermedad.

Financiación. P08-CVI-04037;RD06/0021/0014ISCIII-RETIC-MICINN (España) y FEDER.

\section{Implicancia de la persistencia de Trypanosoma cruzi en la miocardiopatía crónica por enfermedad de Chagas}

Carolina Bazán, Lorena Micucci, Romina Fauro,

Fernanda Triquel, David Cremonezzi,

Silvina Lo Presti, Alejandra Baez, Mariana Strauss,

Patricia Paglini-Oliva, H. Walter Rivarola

Facultad de Ciencias Médicas, Universidad Nacional de Córdoba, y Universidad Nacional de La Rioja, Argentina

Introducción. Los mecanismos por los cuales los pacientes con infección crónica desarrollan la enfermedad de Chagas no son completamente conocidos. Se ha planteado la posibilidad de una patogenia autoinmune, aunque existen dudas de que el mecanismo autorreactivo sea el único responsable de las lesiones cardíacas. Para otros, la persistencia del parásito generaría una reacción inflamatoria crónica, y ésta induciría una respuesta inmune cuyo blanco sería el propio tejido del huésped. Estudiamos la importancia de la persistencia del parásito como factor determinante en generar miocardiopatía.

Materiales y métodos. Se infectaron 139 ratones albinos suizos con 50 tripomastigotes por ratón de Trypanosoma Cruzi, cepa Tulahuen, y se les practicaron electrocardiogramas y se determinó parasitemia, supervivencia, histopatología, inmunofluorescencia y PCR a los 90, 180, 270 y 360 días 
después de la infección. Los datos se analizaron de acuerdo con la naturaleza de la variable en estudio (ANAVA, datos categóricos y test de comparaciones múltiples). Se consideró un nivel de significación de $p<0,05$.

Resultados. La máxima parasitemia se observó a los 21 después de la infección y se volvió negativa a los 42 después de la infección. Las alteraciones en el electrocardiograma en ratones infectados fueron de $50 \%$ a los 90 después de la infección y de $67 \%$ a los 360 después de la infección, y de $9,68 \%$ en ratones sin infectar. Se observaron infiltrados inflamatorios a lo largo de toda la infección, con un mayor porcentaje en aquellos ratones con alteraciones electrocardiográficas; se verificó la presencia de parásitos en el músculo esquelético y cardiaco hasta los 360 después de la infección mediante inmunofluorescencia y PCR. La mayor mortalidad se produjo a los 21 después de la infección con una supervivencia del $10 \%$ al final de la infección.

Conclusiones. Estos resultados demuestran la presencia de parásitos en los tejidos cardíaco y esquelético durante toda la infección y que en la fase crónica indeterminada (ratones sin alteraciones ECG) ya podemos encontrar infiltrados inflamatorios en el miocardio.

\section{Participación de metaloproteasas 2 y 9 durante la infección ex vivo de vellosidades coriónicas placentarias humanas con Trypanosoma cruzi}

Christian Castillo, Juan Duaso, Arturo Villarroel, Erika Yánez, Gonzalo Cabrera, Juan Diego Maya, Norbel Galanti, Ulrike Kemmerling Instituto de Ciencias Biomédicas, Facultad de Medicina, Universidad de Chile, Santiago, Chile

Introducción. La enfermedad de Chagas congénita es causada por el parásito hemoflagelado Trypanosoma cruzique alcanza al feto atravesando la barrera placentaria. Para estudiar parte de los mecanismos celulares y tisulares de la infección placentaria, analizamos la expresión y actividad de las metaloproteinasas 2 y 9 en las vellosidades coriónicas placentarias humanas así como las alteraciones de la matriz extracelular del tejido conjuntivo fetal.

Materiales y métodos. Se obtuvieron tripomastigotes de la cepa DM28c a partir de células Vero infectadas y placentas de término de madres sanas. Se incubaron trozos de tejido placentario $\left(0,5 \mathrm{~cm}^{3}\right)$ durante 24 horas en presencia y ausencia de $10^{5}$ y $10^{6}$ tripomastigotes así como de doxiciclina 100 $\mu \mathrm{M}$ (inhibidor de metaloproteinasas). La infección placentaria se comprobó mediante detección del parásito por PCR.

La expresión de metaloproteinasas fue analizada mediante Western blot e inmunohistoquímica.

La actividad fue determinada mediante fluorescencia (Kit InnoZyme Gelatinase (MMP-2/MMP-9) Activity (Calbiochem®)) y zimografía. Las alteraciones de la matriz extracelular fueron analizadas histoquímicamente mediante tinción de ácido periódico de Schiff (PAS) y de picro rojo sirio.

Resultados. La infección ex vivo de vellosidades coriónicas humanas con tripomastigotes de $T$. cruzi induce aumento de la expresión y actividad de las metaloproteinasas 2 y 9 . La doxicilina inhibe la actividad de las enzimas y revierte parcialmente la desorganización de la matriz extracelular, específicamente la destrucción de moléculas "glucosiladas" (PAS) así como de colágeno I (picro rojo sirio). Sin embargo, la doxicilina no afecta la expresión de las metaloproteinasas ni impide la infección del tejido.

Conclusión. La activación de metaloproteinasas endógenas del huésped constituyen parte de los mecanismos de infección tisular de $T$. cruzi.

Financiamiento: Proyectos Bicentenario Anillo ACT112, Proyectos FONDECYT 11080166 (UK), 1090078 (JM) y 1090124 (NG)

\section{Funcionalidad de los pseudogenes procesados de la familia MASP de Trypanosoma cruzi}

L. M. De Pablos, V. Seco Hidalgo, M. Gómez Samblás, A. Osuna

Grupo de Bioquímica y Parasitología Molecular, Instituto de Biotecnología, Universidad de Granada, Granada, España

Introducción. La fuerte presión y la rápida evolución de las familias multigénicas generan un gran número de pseudogenes, que se definen como secuencias con codones prematuros de parada. Se ha demostrado que existen pseudogenes pertenecientes a organismos multicelulares que actúan como reguladores postranscripción de la expresión génica. El $31 \%$ de la familia multigénica MASP de Trypanosoma cruzi son pseudogenes sobre los que todavía no existe una funcionalidad asignada.

Materiales y métodos. Todas las amplificaciones a partir de cDNA de la fase tripomastigote metacíclico de las cepas PAN4 (DTU I) CL-Brener 
(DTU IV) y Maracay (DTUI-DTU-II) fueron clonadas en vectores pGEM-T Easy. Para los análisis de expresión utilizamos ensayos de RTqPCR. Además, se realizaron ensayos de protección de RNA, Southern y Northern blots para el análisis de los dúplex RNA-RNA.

Resultados. Se clonaron 7 PS MASP transcritos MASP, que mostraron en sus secuencias sitios específicos de inserción para el retroelemento TcTREZO, lo que los clasifica como pseudogenes procesados por retrotransposición. Tras usar como modelo de estudio de los dúplex de RNA el PS masp2PS1CL, encontramos la existencia de un dúplex de 173 pb estable tras el tratamiento con RNasa A. Esta secuencia híbrida ofrecía un grado de homología muy alto entre 8 cepas de diferentes unidades discretas de tipificación (Discrete Typing Units, DTU). También se encontró una diferente expresión de masp2PS1CL por RTqPCR, lo que indica su regulación diferencial.

Conclusiones. En el presente trabajo se demuestra que $T$. cruzi expresa parte de su pseudogenoma MASP y que éste puede tener una funcionalidad como regulador de la expresión génica, mecanismo necesario para la supervivencia de $T$. cruzi dada la importancia que la regulación postranscripción tiene en este parásito.

\section{Infección de astrocitos humanos por Trypanosoma cruzi}

Juan C. Vargas ${ }^{1}$, Paola Lasso², Adriana Cuéllar ${ }^{3}$, Concepción J. Puerta², John M. González ${ }^{1}$

1 Grupo de Ciencias Básicas Médicas, Facultad de Medicina, Universidad de los Andes, Bogotá,

D.C., Colombia

${ }^{2}$ Laboratorio de Parasitología Molecular, Departamento de Microbiología, Facultad de Ciencias,

Pontificia Universidad Javeriana, Bogotá, D.C., Colombia

${ }^{3}$ Grupo de Inmunobiología y Biología Celular, Facultad de Ciencias, Pontificia Universidad Javeriana, Bogotá, D.C., Colombia

Introducción. Trypanosoma cruzi puede producir infección en el sistema nervioso central, especialmente durante el cuadro agudo o en individuos inmunosuprimidos. La patogénesis de la infección no es bien conocida, sin embargo, en animales se describe infección de la glía.

En este trabajo, se estudia la infección in vitro por $T$. cruzi de astrocitos humanos.

Materiales y métodos. La línea tumoral de astrocitos humanos CRL-1718 se infectó con tripomastigotes de $T$. cruzi del aislamiento MHOM/ CO/01/DA, evaluándose los cultivos a los días 2, 4 y 6 después de la infección. La infección celular y la presencia de amastigotes se determinaron mediante tinción con Giemsa. La expresión de moléculas del complejo mayor de histocompatibilidad (HLA) fue evaluada por citometría de flujo y la mortalidad, usando tinción azul de tripano.

Resultados. Al día 2 después de la infección, el porcentaje de células infectadas fue de 18,4\% y el promedio de parásitos por célula $6,8( \pm 3,9)$, cifras que incrementaron al día 6 hasta $93 \%$ y 78,1 $( \pm 80,3)$, respectivamente. La mortalidad celular al día 2 en el control (astrocitos no infectados) fue de $2,2 \%$ y en las células infectadas, de $5 \%(p=0,6)$; al día 4 , en los controles, 1,2\%, e infectadas, 5,1,\% $(p=0,28)$, y al día 6 , en el control, $0,75, \%$, y en las infectadas, 8,8 \% $(p=0,015)$. La expresión de HLA de clase I fue similar para controles y células infectadas en los tres días (97,8\% Versus $96,3 \%)$, en tanto que la expresión de HLA-DR aumentó en las células infectadas de $0,8 \%$ a $1,4 \%(p=0,04)$ al día 2 y a $2,45 \%(p=0.0001)$ al día 4 , disminuyendo a $0,57 \%(p=0,18)$ al día 6 .

Conclusiones. Trypanosoma cruzi infecta, prolifera y aumenta la expresión de HLA-DR en astrocitos humanos. Siendo una célula huésped del parásito en el sistema nervioso central, la presentación antigénica mediante HLA de clase II podría estar implicada en las primeras etapas de la respuesta inmunitaria.

\section{El análisis mediante PCR-RFLP multiloci en Trypanosoma cruzi I sugiere un patrón de variación genética intraespecífica.}

Juan David Ramírez, Felipe Guhl

Centro de Investigaciones en Microbiología y

Parasitología Tropical, Universidad de los Andes, Bogotá, D.C., Colombia

Introducción. La enfermedad de Chagas causada por Trypanosoma cruzi es considerada un problema importante de salud pública. Este parásito es altamente polimórfico y subdividido en seis unidades discretas de tipificación. Trypanosoma cruzi I (Tcl) es la unidad discreta de tipificación más prevalente en Colombia y, recientemente, asociada a daños cardíacos. Esta unidad discreta de tipificación ha sido dividida en cinco genotipos asociados a los ciclos de transmisión de la enfermedad de Chagas, usando la región intergénica del gen miniexón (SL-IR).

El objetivo de este trabajo fue implementar una estrategia de PCR-RFLP multiloci para corroborar 
la diversidad genética de esta unidad discreta de tipificación.

Materiales y métodos. Se analizaron 70 clones de $\mathrm{Tcl}$ aislados de humanos, vectores y reservorios. Se amplificaron diez regiones genómicas (1f8, Gp72, Gp63, SAPA, ITS, H1, H3, HSP60, HSP70, GPI). Los productos se digirieron con endonucleasas de restricción. Los patrones de restricción se analizaron y se construyeron dendrogramas para evidenciar la distancia genética entre los clones. Se construyeron dendrogramas por cada región analizada y un árbol consenso de distancias genéticas.

Resultados y conclusiones. A partir de los patrones de restricción, sólo cuatro regiones fueron polimorfas (1f8, H1, SAPA, HSP60). En el árbol consenso, usando las diez regiones, se determinaron dos grupos: el grupo 1 asociado a clones aislados de vectores y reservorios selváticos, y el grupo 2 asociado a clones aislados de infecciones humanas, vectores y reservorios peridomésticos.

Este trabajo corrobora los genotipos previamente reportados utilizando la región SL-IR. Esta es la primera vez que se realiza una estrategia multiloci con regiones codificantes para evidenciar la variabilidad de $\mathrm{Tcl}$; estos resultados sugieren un patrón de variación intraespecífica en Tcl y muestra la necesidad de conocer más a fondo la epidemiología molecular de esta unidad discreta de tipificación en el continente americano.

\section{Variabilidad genética de poblaciones colombianas de Trypanosoma cruzi I mediante análisis de los genes citocromo b y SSU ADNr}

Juan David Ramírez, María Clara Duque, Felipe Guhl Centro de Investigaciones en Microbiología y

Parasitología Tropical, Universidad de los Andes, Bogotá, D.C., Colombia

Introducción. La enfermedad de Chagas es una antropozoonosis ocasionada por el parásito Trypanosoma cruzi. Este protozoario presenta una alta variabilidad genética evidenciada en seis unidades discretas de tipificación. En Colombia, la principal unidad discreta de tipificación es $T$. cruzil (Tcl). Se ha demostrado la alta variabilidad genética en Tcl mediante el análisis de la región intergénica del gen miniexón $(S L-I R$ ) y se han encontrado cinco genotipos asociados con los ciclos de transmisión. $\mathrm{Tcl}$ ha ganado importancia recientemente debido a su asociación con cardiopatías en Colombia y Argentina.
El objetivo de este estudio fue evaluar la variabilidad genética en clones de aislamientos colombianos provenientes de humanos, reservorios y vectores de Tcl.

Materiales y métodos. Se analizaron 70 clones colombianos de $\mathrm{Tcl}$ aislados de humanos, vectores y reservorios provenientes de diferentes regiones geográficas. Los clones fueron caracterizados como Tcl mediante $S L-I R$ y amplificación del dominio 24S ADNr. Se secuenciaron los genes citocromo b (Cytb) y la región V7-V8 del SSU ADNr. Las secuencias fueron editadas en MEGA 5.0 y alineadas en Clustal W. Las secuencias se concatenaron en SeaView 2.0 y se realizo una reconstrucción filogenética mediante un análisis de máxima verosimilitud con 1.000 réplicas. Además, se construyó una red de haplotipos mediante el algoritmo de vectores mediados en Network 2.0.

Resultados y conclusiones. De acuerdo con la topología del árbol de máxima verosimilitud, se detectaron tres genotipos asociados a los ciclos de transmisión de la enfermedad de Chagas en Colombia. El genotipo 1 asociado a infecciones humanas, el genotipo 2 asociado a clones aislados de reservorios y vectores peridomésticos y el genotipo 3 asociado a clones aislados de reservorios y vectores selváticos.

Estos genotipos son concordantes con los reportados usando la región SL-IR lo que sugiere la alta variabilidad intraespecífica dentro de Tcl y muestra la necesidad de continuar los estudios en países donde la enfermedad de Chagas es endémica con el objetivo de elucidar la epidemiología molecular de esta unidad discreta de tipificación.

\section{Análisis histopatológico comparativo de placentas de madres con enfermedad de Chagas y de explantes placentarios de madres sanas e infectadas ex vivo con Trypanosoma cruzi}

Juan Duaso, Erika Yánez, Christian Castillo, Arturo

Villarroel, Gonzalo Cabrera, Werner Apt,

Inés Zulantay, Juan Diego Maya, Norbel Galanti, Ulrike

Kemmerling

Instituto de Ciencias Biomédicas, Facultad de Medicina, Universidad de Chile,

Santiago, Chile

Introducción. La enfermedad de Chagas congénita es causada por el parásito hemoflagelado Trypanosoma cruzi; este alcanza al feto por vía 
sanguínea atravesando la barrera placentaria. Trypanosoma cruzi induce desprendimiento del trofoblasto, destrucción selectiva de los componentes de las láminas basales y desorganización del colágeno I del tejido conjuntivo fetal durante la infección ex vivo de vellosidades coriónicas placentarias humanas.

Sin embargo, no se han estudiado estas alteraciones en placentas de mujeres infectadas con $T$. cruzi.

Materiales y métodos. Se obtuvieron tripomastigotes de la cepa Y a partir de células Vero infectadas y placentas de término de madres sanas.

Se incubaron trozos de tejido placentario $\left(0,5 \mathrm{~cm}^{3}\right)$ durante 24 horas en presencia y ausencia de $10^{5}$ tripomastigotes.

Las muestras de placentas de madres con enfermedad de Chagas crónica se obtuvieron en el Hospital de Illapel, IV Región, Chile. La infección placentaria se comprobó mediante detección del parásito por PCR e inmunofluorescencia (Ac antiflagellar calcium binding protein).

Se efectuaron estudios histopatológicos (hematoxilina y eosina), inmunohistoquímicos de las láminas basales (colágeno IV, heparán-sulfato y fibronectina) así como histoquímicos de moléculas "glucosiladas" (ácido periódico de Schiff) y para colágeno (Arteta y picro rojo sirio)

Resultados. Se detectaron antígenos parasitarios tanto en las placentas de las madres con enfermedad de Chagas como en explantes infectados ex vivo.

Las placentas infectadas con el parásito presentaron un acentuado daño tisular, observándose desprendimiento y destrucción del trofoblasto, además de desorganización del tejido conjuntivo fetal.

Los análisis histoquímicos demostraron una menor reacción para las moléculas "glucosiladas" y los colágenos. En los estudios inmunohistoquímicos se observó una menor inmunoreacción para el colágeno IV y el heparán-sulfato y ningún cambio para la fibronectina.

Conclusiones. Las placentas de madres con enfermedad de Chagas muestran alteraciones similares a las placentas infectadas ex vivo, lo que valida el modelo de infección ex vivo tanto para estudiar los mecanismo de infección parasitaria como los mecanismos antiparasitarios placentarios locales.

Financiamiento: Proyectos Bicentenario Anillo ACT112, Proyectos FONDECYT 11080166 (UK), $1090078(\mathrm{JM})$ y 1090124 (NG)

\section{Análisis de los genes de la} transialidasa en aislamientos de Trypanosoma cruzi obtenidos de pacientes con enfermedad de Chagas

Nelson A. Salazar ${ }^{1}$, Rubén S. Nicholls ${ }^{2}$, Marleny

Montilla ${ }^{2}$

${ }^{1}$ Facultad de Medicina, Universidad Militar Nueva Granada Bogotá, D.C., Colombia

${ }^{2}$ Grupo de Parasitología, Instituto Nacional de Salud, Bogotá, D.C., Colombia

Introducción. La transialidasa es uno de los factores de virulencia más importantes y estudiados de Trypanosoma cruzi y uno de los más prometedores candidatos para el diseño de una vacuna contra la enfermedad de Chagas o de un medicamento. El estudio de su variabilidad genética en aislamientos clínicos es crucial para mapear regiones que puedan ser relevantes en esos diseños.

Materiales y métodos. Se utilizaron 14 aislamientos de $T$. cruzi provenientes de pacientes con enfermedad de Chagas de diferentes regiones de Colombia. Se aislaron ARN totales de los epimastigotos y se usaron como plantillas para amplificar fragmentos de 966 bp mediante RT-PCR. Se secuenciaron dichos fragmentos que cubren toda la región catalítica de la transialidasa (aminoácidos 328 al 528). También se realizaron ensayos de contagiosidad y análisis histopatológicos. Se buscaron relaciones entre le origen, la contagiosidad, los hallazgos histopatológicos y moleculares mediante la prueba de Fisher.

Resultados. Encontramos 50 polimorfismos de un solo nucleótido que resultan en cambios de aminoácido. Todos los 14 fragmentos codifican para proteínas con actividad enzimática, pues presentan la tirosina 367 que les da esa característica. También presentaron los motivos típicos de la transialidasa del grupo 1 como el epítopo de células T CD8+ (IYNVGQVSI), la caja de asparagina IV (SYDEKHQW) y el motivo LYN. El epítopo ANYNFTLV que induce la más fuerte respuesta inmunitaria de células T CD8+ en pacientes agudos con enfermedad de Chagas, se encontró en siete de los aislamientos con 7 de sus 8 aminoácidos (ANYEFTLV); mientras que seis de los aislamientos presentaron el motivo ANHAFTLV que no ha sido reportado antes. No encontramos ninguna relación entre los hallazgos moleculares y las diferentes características de los aislamientos usando la prueba de Fisher. 
Conclusiones. Aunque existe una gran variabilidad genética en las secuencias de transialidasa en aislamientos clínicos, también hay regiones conservadas con epítopos importantes en el diseño de vacunas contra la enfermedad de Chagas. Este trabajo es la primera caracterización molecular de la transialidasa en aislamientos de pacientes con enfermedad de Chagas en Colombia.

\section{$\bullet \bullet$ \\ Expressão heteróloga de transialidases de Trypanosoma cruzi por Trypanosoma rangeli}

Ninna Granucci', Patrícia Hermes Stoco ${ }^{1}$, Thaynara Karoline de Souza Pereira ${ }^{1}$,

Sergio Schenkman ${ }^{2}$, Edmundo Carlos Grisard ${ }^{1}$

1 Departamento de Microbiologia, Imunologia e

Parasitologia, Universidade Federal de Santa

Catarina, Florianópolis, Brasil

2 Departamento de Microbiologia, Imunologia e

Parasitologia, Universidade Federal de São Paulo,

São Paulo, Brasil.

Introdução. O Trypanosoma rangeli compartilha distribuição geográfica, reservatórios e vetores com o Trypanosoma cruzi, agente etiológico da doença de Chagas. As transialidases de T. cruzi, enzimas capazes de transferir ácidos siálicos, estão relacionadas ao processo de interação, penetração do parasito na célula hospedeira e seu escape do vacúolo fagocítico. O $T$. rangeli, embora não patogênico ao hospedeiro mamífero, possui alguns genes da família das transialidases, entretanto não possui nenhuma atividade transferência como perfaz algumas transialidases de T. cruzi (TcTS).

O objetivo do presente estudo foi expressar transialidases de $T$. cruzi em $T$. rangeli para a geração de uma ferramenta para estudos da interação celular patógeno-hospedeiro.

Materiais e métodos. Para tanto, foram realizadas construções plasmidiais contendo o gene da transialidase (ativa) de $T$. cruzi ou o gene inativo da transialidase (TcTS2V $\varnothing$ ), ambas em uma versão modificada do plasmídeo de expressão pTEX-eGFP. Ensaios de imunofluorescências e Western blot foram realizados utilizando soro policlonal direcionado para o sítio catalítico e anticorpo monoclonal para o terminal repetitivo SAPA (mAb39). Ensaios de atividade transialidase foram realizados nos parasitos transfectados.

Resultados. Os ensaios de Western blot permitiram confirmar a expressão heteróloga de uma proteína de $\sim 75 \mathrm{kDa}$ nos parasitos transfectados, o que esta de acordo com o esperado teórico. E utilizando a técnica de imunofluorescência foi possível observar que parte das proteínas expressa está sendo direcionada para a membrana do parasita. Nos ensaios de atividade realizados, evidenciou-se que o $T$. rangeli que expressa de forma heteróloga a TcTS possui atividade de transferir os ácidos siálicos.

Conclusão. Os resultados confirmarama expressão heteróloga da TcTS de $T$. cruzi por $T$. rangeli, além de apontar que o parasito transfectado possui uma transialidase ativa.

\section{Identificación de la expresión y de la actividad de la endonucleasa de reparación del DNA TcAP1 en Trypanosoma cruzi}

Sofia Sepúlveda, Iván Ponce, Lucía Valenzuela, José Delgadillo, Santiago Ramírez, Soledad Sierra, Paula Bahamondes, Natalia Muñoz, Ulrike Kemmerling, Gonzalo Cabrera, Norbel Galanti Instituto de Ciencias Biomédicas, Facultad de Medicina, Universidad de Chile, Santiago, Chile

Introducción. Trypanosoma cruzi sobrevive a especies reactivas en el insecto vector y en el huésped mamífero. Proponemos que el daño por oxidación del ADN parasitario es reparado por el sistema de escisión de bases.

En este trabajo se detectó actividad endonucleasa apurínica/apirimidínica, la expresión de la endonucleasa TcAP1 en las tres formas celulares del parásito y el nivel de expresión de TcAP1 en epimastigotes expuestos a agentes oxidantes.

Materiales y métodos. Para detectar actividad endonucleasa apurínica/apirimidínica se sintetizó un oligonucleótido de 22-mer con un sitio abásico en posición 7. Se marcó el extremo 5' con P32 y se alineó con la hebra complementaria no marcada. Posteriormente, el oligonucleótido se incubó con homogeneizados de epimastigotes, tripomastigotes y amastigotes. Los fragmentos se evidenciaron por electroforesis en condiciones desnaturalizadoras y autorradiografía. La presencia y niveles de expresión de TcAP1 se determinó en homogeneizados de las tres formas celulares de T. cruzi por Western blot empleando un anticuerpo específico. El nivel de expresión de TcAP1 se midió en homogeneizados de epimastigotes expuestos a $\mathrm{H}_{2} \mathrm{O}_{2}$.

Resultados. Epimastigotes, tripomastigotes y amastigotes presentan actividad endonucleasa apurínica/apirimidínica, evidenciado por la presencia de una banda de 7-mer.

Trypanosoma cruzi expresa TcAP1 en todas sus formas celulares. Esta proteína no incrementa su expresión frente al estrés por oxidación en 
epimastigotes, en las condiciones experimentales utilizadas.

Conclusiones. Se detectó actividad endonu-cleasa apurínica/apirimidínica y expresión de la enzima TcAP1 en las tres formas celulares del parásito. No se evidenciaron variaciones en los niveles de expresión de TcAP1 frente a agentes oxidantes.

$$
\text { - } \bullet
$$

\section{Las enzimas de reparación del ADN TcAP1 Y TcAP2 se localizan en el núcleo y el aumento de su expresión incrementa la viabilidad de los epimastigotes de Trypanosoma cruzi frente al estrés por oxidación.}

Sofía Sepúlveda, Lucía Valenzuela, Iván Ponce, José Delgadillo, Santiago Ramírez, Soledad Sierra, Paula Bahamondes, Natalia Muñoz, Ulrike Kemmerling, Norbel Galanti, Gonzalo Cabrera

Instituto de Ciencias Biomédicas, Facultad de Medicina, Universidad de Chile,

Santiago, Chile

Introducción. La vía de reparación del ADN por escisión de bases es uno de los mecanismos por los cuales Trypanosoma cruzi podría sobrevivir al daño inducido por el estrés por oxidación. Las endonucleasas apurínicas/apirimidínicas son críticas en la vía de reparación del ADN por escisión de bases.

En este trabajo se determinó la localización subcelular de TcAP1 y TcAP2 (endonucleasas apurínicas/apirimidínicas de T. cruzi) y su efecto en la viabilidad de epimastigotes que aumentan la expresión de ambas enzimas.

Materiales y métodos. Se utilizó el vector de expresión pTREX-GFP para inducir el aumento de la expresión de TcAP1 y TcAP2 en epimastigotes, evaluada mediante Western blot utilizando un anticuerpo anti-GFP. La localización subcelular de ambas enzimas se determinó mediante microscopía de fluorescencia. La viabilidad de los parásitos recombinantes y los controles sometidos a tratamientos con agentes oxidantes se determinó por ensayos de MTT.

Resultados. Se obtuvieron cepas recombinantes de epimastigotes de $T$. cruzi que aumentan la expresión de las proteínas TcAP1-GFP y TcAP2GFP con una masa molecular mayor pero cercana a la esperada. A diferencia de eucariontes recientes, las endonucleasas apurínicas/apirimidínicas de T. cruzi (TcAP1 y TcAP2) se localizan sólo en el núcleo de los epimastigotes transfectados. La sobreexpresión de TcAP1 y en menor medida de
TcAP2 produce un incremento en la viabilidad de epimastigotes de $T$. cruzi sometidos a estrés por oxidación.

Conclusión. Estos resultados sugieren que TcAP1 y TcAP2 presentan un rol importante en la resistencia de $T$. cruzial daño por oxidación al ADN, situándolas como un posible blanco terapéutico para el tratamiento de la enfermedad de Chagas.

Financiamiento: Proyecto FONDECYT 11100053 (GC)

Beca de apoyo para la tesis doctoral CONICYT 24110156 (SS)

\section{Role as immunomodulator of an amastigote stage-specific derived recombinant protein of Trypanosoma cruzi in the mouse model}

Yevel Flores-García, José Luis Rosales-Encina, Víctor Rosales-García, Patricia Talamás-Rohana

Departamento de Infectómica y Patogénesis Molecular, CINVESTAV-IPN,

México, D.F., México

Introduction. During the acute phase of infection, Trypanosoma cruzi replicates extensively and releases immunomodulatory molecules that delay parasite-specific responses mediated by effector $T$ cells. This mechanism of evasion allows the parasite to spread in the host. Parasite molecules that regulate the host immune response during Chagas' disease have not been fully identified.

The aim of this work was to assess the role of rMBP:SSP4 protein in the mouse model.

Material and methods. BALB/c mice were immunized three times $(10 \mu \mathrm{g} /$ dose $)$, once a week with rMBP:SSP4 protein. After the last immunization, proliferation assays were developed in order to analyze the immune response induced in spleen cells. Different cytokines were measured by ELISA and the presence of regulatory $\mathrm{T}$ cells was measured, and their suppressive function too. We also evaluated the role of passively transferred Treg cells during acute infection development.

Results. rMBP:SSP4 was able to induce high levels of mRNA TGF- $\beta$ expression, and IL-10 and TGF- $\beta$ secretion by spleen cells, being more abundant in those cells from immunized mice than in those from non immunized mice. Regarding Treg cells, we found higher percentage of CD4+CD25+FOXP3+ Treg cells in immunized mice than in non immunized mice, these cells possess suppressive function confirmed by inhibition of effector $T$ cells proliferation. Finally, the role of Treg cells during 
acute trypanosomiasis was evaluated. Results showed that these cells increase the parasitemia and survival of mice that were passively transferred with Treg cells that came from immunized mice Conclusions. Results indicate that rMBP:SSP4 protein is able to induce the presence of immunomodulatory cytokines and the presence of Treg cells populations as a mechanism of host immune response modulation. 


\section{Enfermedad de Chagas \\ Diagnóstico y Tratamiento}

\section{Recopilación bibliográfica de fármacos utilizados hasta nuestros días para tratar la enfermedad de Chagas-Mazza}

\author{
Aldo Rodríguez \\ Departamento de Biología, Facultad de Ciencias, \\ Universidad de Los Andes, \\ Bogotá, D.C., Colombia
}

Introducción. La enfermedad de Chagas, o tripanosomiasis americana, es una afección parasitaria tropical causada por un protozoario llamado Trypanosoma cruzi. Es transmitida al hombre, principalmente, por la picadura y luego contacto con las heces de insectos del orden Hemiptera, como Triatoma dimidiata, Triatoma brasiliensis, Panstrongylus megistus, Rhodnius prolixus y Triatoma infestans, ingresando los parásitos por la herida causada hasta llegar al torrente sanguíneo, desde donde viajará a los diferentes tejidos y órganos, para luego replicarse. Causa cardiopatía por la enfermedad de Chagas, daños en los plexos mientéricos del tracto gastrointestinal y hace que las personas presenten un crecimiento exagerado del colón y del esófago. Hasta nuestros días se han detectado cerca de 12 millones de casos en el continente americano, por lo tanto, su tratamiento se ha convertido en un problema de salud pública.

La aparición del nifurtimox en 1965 comprobó que las personas infectadas durante la etapa aguda de la infección presentaban resultados negativos en los exámenes parásitologicos seriados y en los serológicos durante meses y, en algunos casos, incluso durante años. En 1971 apareció el benznidazol, cuya eficacia fue similar o superior en pacientes tratados durante la fase aguda. Hace ya una década que se conocen las reacciones adversas que tienen el nifurtimox y el benznidazol, causando alteraciones generales como baja de peso, malestar gástrico, náuseas y dermatitis atópica, hasta alteraciones complejas como síndrome de Stevens Johnson, en algunos casos, y polineuropatías dependientes de las dosis. Otro fármaco utilizado es el alopurinol que inhibe la síntesis de proteínas y purinas, lo que trae como consecuencia la falla en la proliferación del parásito ya que es incapaz de sintetizar purinas.
El itraconazol y el posaconazol son inhibidores de la síntesis de ergoesterol, T. cruzi tiene ergosterol y los antimicóticos impiden su síntesis sin afectar al huésped humano que tiene colesterol. Por lo tanto, es necesario adoptar nuevas alternativas para suministrar tratamientos a los pacientes en distintas fases de la enfermedad (aguda, crónica reciente, crónica tardía e infección congénita).

Materiales y métodos. Este trabajo se realizó mediante una revisión bibliográfica de los medicamentos que se han venido utilizando para los tratamientos de la enfermedad de Chagas, a fin de dar a conocer de una manera pedagógica y didáctica con lo que contamos hasta el momento.

Resultados. Diversos estudios revelaron que de los medicamentos existentes hasta el momento, POSA, ravuconazol, VR-9825 y TAK-187 tienen acción sobre cepas de $T$. cruzi parcialmente resistentes al nifurtimox, al benznidazol y donde el ketoconazol no tiene rendimiento.

Hasta el momento, los fármacos más utilizados por razones de efectividad, ética y de mercadeo que se utilizan en la enfermedad de Chagas humana son el nifurtimox (Lampitß, Bayer) y el benznidazol (Ragonil@, Rochagan®, Roche). Ambos producen efectos colaterales especialmente en adultos, ya que los recién nacidos y los niños menores toleran mucho mejor los fármacos.

Conclusiones. Luego de acumular conocimiento sobre la biología y la bioquímica de $T$. cruzi, se vuelve cada día más urgente la agregación y convergencia de esfuerzos dirigidos a la comprensión de los mecanismos de acción de potenciales compuestos o vías metabólicas contra este parásito.

Una línea actualmente en desarrollo está relacionada con la elaboración de medicamentos que puedan ser dirigidas a sitios específicos, tanto del parásito como del huésped. Otros estudios recientes que han dado más respuestas a interrogantes, son los basados en identificar blancos potenciales en $T$. cruzi, que incluyen metabolismos de esteroles, ADN y diferentes enzimas. 


\section{Mutaciones en la enzima nitrorreductasa I de Trypanosoma cruzi en respuesta a presiones con benznidazol}

Ana María Mejía ${ }^{1,2}$, Belinda S. Hall ${ }^{3}$, Martin C. Taylor ${ }^{1}$, Shane R. Wilkinson ${ }^{3}$, Omar Triana ${ }^{2}$, John M. Kelly ${ }^{1}$

${ }^{1}$ London School of Hygiene and Tropical Medicine, London, UK

2 Grupo BCEI, Universidad de Antioquia, Medellín, Colombia

${ }^{3}$ Queen Mary University of London, London, UK

Introducción. El benznidazole y el nifurtimox son medicamentos utilizados para tratar las infecciones por Trypanosoma cruzi. Ambos compuestos son profármacos y necesitan ser activados en el parásito por la enzima nitrorreductasa mitocondrial tipo I (TcNTR). La pérdida o alteración de una de las copias del gen es suficiente para causar resistencia cruzada a estos compuestos nitroheterocíclicos.

El objetivo de este trabajo fue analizar los diferentes parámetros biológicos de parásitos sensibles y resistentes inducidos al benznidazol en T. cruzi y caracterizar el gen TcNTR en estas poblaciones.

Materiales y métodos. Luego de generar una línea resistente de parásitos a una presión con benznidazol de $50 \mu \mathrm{M}$, los parásitos sensibles y resistentes se clonaron y se caracterizó la enzima TcNTR por técnicas de electroforesis de campo pulsado, secuenciación, análisis de la proteína recombinante, aumento de la expresión del gen en parásitos resistentes y alteración del mismo en los sensibles. Además, se evaluaron algunos parámetros biológicos como el crecimiento in vitro y la infección a las células de mamífero.

Resultados. Los análisis por electroforesis de campo pulsado evidenciaron la pérdida de una copia del gen TcNTR en el cromosoma homólogo de menor tamaño en los parásitos resistentes. El análisis de la copia remanente evidenció la presencia de mutaciones puntuales y la falta de actividad de las proteínas recombinantes mutantes por pérdida de unión con el cofactor FMN. El fenotipo resistente fue revertido con la introducción del gen y generado al dañar una de las copias del gen de parásitos sensibles. Finalmente, el crecimiento in vitro disminuyó ligeramente en el fenotipo resistente, al igual que la cantidad de células infectadas.

Conclusión. Estos resultados muestran que TcNTR tiene un papel fundamental en la inducción de la resistencia al benznidazol. Además, se demuestra que $T$. cruziresponde con cambios genéticos rápidos para generar la resistencia al medicamento.

\section{Eficacia del tratamiento etiológico con nifurtimox contra la enfermedad de Chagas en escolares de Casanare: primera fase}

Fiorella Bianchi ${ }^{1}$, Lorena González ${ }^{1}$, Juan David Ramírez ${ }^{1}$, Marleny Montilla², Zulma Cucunubá2, Carolina Flórez², Fernando Rosas ${ }^{3}$, Héctor Freilij ${ }^{4}$, Nubia Silva ${ }^{5}$, Víctor Saavedra ${ }^{6}$, Luis Eduardo Castro ${ }^{7}$, Felipe Guhl ${ }^{1}$

1 Centro de Investigaciones en Microbiología y Parasitología Tropical, Universidad de los Andes, Bogotá, D.C., Colombia

${ }^{2}$ Grupo de Parasitología, Instituto Nacional de Salud, Bogotá, D.C., Colombia.

${ }^{3}$ Electrofisiología, Clínica Abood Shaio, Bogotá, D.C., Colombia

${ }^{4}$ Hospital Ricardo Gutiérrez, Buenos Aires, Argentina

5 ServinSalud Ltda., Yopal, Colombia

${ }^{6}$ Hospital San Silvestre, Yopal, Colombia

7 Secretaría de Salud, Yopal, Colombia

Introducción. La enfermedad de Chagas se encuentra distribuida en el continente americano, en donde se estima que cerca de 12 millones de personas se encuentran infectadas con el agente causal Trypanosoma cruzi. Se recomienda la aplicación del tratamiento etiológico en las fases más tempranas de la enfermedad, aguda o indeterminada. Actualmente, existen dos tratamientos contra T. cruzi: el nifurtimox (Lampit@) y el benznidazol (LAFEPE). La Organización Mundial de la Salud ha recibido una donación de nifurtimox y, actualmente, es el único tratamiento que está disponible en el país.

El objetivo de este proyecto fue realizar un estudio piloto para evaluar la eficacia y seguridad del tratamiento con nifurtimox en escolares que habitan un área endémica de Colombia.

Materiales y métodos. Se incluyeron 62 escolares, 53 del municipio de Nunchía y 9 del municipio de Yopal, a los cuales se les realizaron pruebas serológicas (IFI) y parasitológicas (PCR y hemocultivo) para el seguimiento del tratamiento y exámenes de laboratorio y electrocardiograma para evaluar la seguridad del tratamiento.

Resultados. Los efectos secundarios al tratamiento que se presentaron en la mayoría de los pacientes, estaban relacionados con el sistema digestivo, como hiporexia, astenia, cefalea y dolor en el abdomen. Los resultados de la PCR convencional al día 0 fueron negativos en $4 \%$, mientras que al día 60 , al finalizar el tratamiento, el $30 \%$ fueron negativos.

Conclusiones. Debido a que se ha demostrado que el tiempo de duración de la seroconversión 
de los pacientes varía según múltiples factores, se debe seguir la evaluación realizando pruebas hasta dos años después del tratamiento. En la segunda fase del proyecto, se realizará la prueba de PCR en tiempo real con el fin de cuantificar la carga parasitaria y observar la evolución de la enfermedad una vez se haya finalizado el tratamiento.

\section{Actividad tripanomicida del éster etílico del ácido $\mathrm{N}$-propil-oxámico y del éster bencílico del ácido N-propil- oxámico en cepas de Trypanosoma cruzi de diferentes estados de la República Mexicana}

J. Luis Téllez-Rendón ${ }^{1}$, Sergio Pastén-Sánchez",

Benjamín Nogueda ${ }^{2}$, Carlos Wong ${ }^{3}$

1 Laboratorio de Entomología y Laboratorio de Chagas, Instituto de Diagnóstico y Referencia Epidemiológicos, México, D.F., México

2 Departamento de Parasitología, Escuela Nacional de Ciencias Biológicas, Instituto Politécnico Nacional, México, D.F., México

${ }^{3}$ Departamento de Bioquímica, Escuela Nacional de Ciencias Biológicas, Instituto Politécnico Nacional, México, D.F., México

Introducción. La enfermedad de Chagas es una zoonosis causada por un hemoflagelado de la familia Trypanosomatidae, especie Trypanosoma cruzi transmitida al hombre y otros vertebrados por insectos vectores de la subfamilia Triatominae.

El objetivo fue determinar el efecto tripanomicida del éster etílico del ácido N-propil-oxámico (NpoxEt) y del éster bencílico del ácido N-propil-oxámico (Npox-B) como posibles profármacos, in vitro sobre epimastigotes de T. cruzi.

Materiales y métodos. Se utilizaron 22 cepas de epimastigotes en medio Warren originarias de 11 estados de la República Mexicana del banco de cepas del Instituto de Diagnóstico y Referencia Epidemiológicos-SSa. El Npox-Et y Npox-B fueron sintetizados en el Laboratorio de Enzimología de la Escuela Nacional de Ciencias Biológicas del Instituto Politécnico Nacional. Se utilizaron también los fármacos convencionales nifurtimox y benznidazol para comparación y control positivo. La cantidad de epimastigotes se ajusto a $5 \mathrm{x}$ $10^{5}$ parásitos por $\mathrm{ml}$ que fueron expuestos a concentraciones finales de 1, 2, y 4 mM de NpoxEt, nifurtimox y benznidazol así como a 0,25, 0,50, 1, 2 y 4 mM de Npox-B.

Resultados. El Npox-B fue el que mayor actividad tripanomicida presentó con $100 \%$ de muerte de los parásitos en la concentración de $4 \mathrm{mM}$, de 95,6 y $68,4 \%$ para las concentraciones de 2 y 1 $\mathrm{mM}$, respectivamente. Para Npox-Et el resultado fue de $73 \%$ (4 mM), 17,14\% (2 mM) y $9,73 \%$ (1 $\mathrm{mM}$ ); estos últimos similares a los presentados por nifurtimox y benznidazol. Se observó una gran variabilidad en las cepas de epimastigotes de $T$. cruzi en cuanto a su comportamiento biológico en medio de cultivo.

Conclusiones. El mayor efecto tripanomicida lo presento Npox-B en las concentraciones de 1, 2 y $4 \mathrm{mM}$ con respecto a los demás fármacos. Npox-Et presentó una actividad tripanomicida similar a los fármacos convencionales la cual, sin embargo, fue baja.

\section{Funcionalidad de anticuerpos contra $\mathrm{K} 1$, un epítopo inmunogénico de la KMP-11 de Trypanosoma cruzi}

Juan Camilo Díaz-Soto ${ }^{1}$, Paola Lasso², Fanny

Guzmán ${ }^{3}$, Manu Forero-Shelton ${ }^{4}$, María del Carmen

Thomas ${ }^{5}$, Manuel Carlos López ${ }^{5}$, Felipe Guhl ${ }^{6}$, Adriana

Cuéllar7, Concepción Judith Puerta², John M. González ${ }^{1}$

1 Grupo de Ciencias Básicas Médicas, Facultad de Medicina, Universidad de los Andes, Bogotá, D.C., Colombia

${ }^{2}$ Laboratorio de Parasitología Molecular, Departamento de Microbiología, Facultad de Ciencias, Pontifica Universidad Javeriana, Bogotá, D.C., Colombia

${ }^{3}$ Laboratorio de Genética e Inmunología Molecular, Núcleo Biotecnología Curauma, Pontificia Universidad Católica de Valparaíso, Valparaíso, Chile

${ }^{4}$ Grupo de Biofísica, Facultad de Ciencias, Universidad de los Andes, Bogotá, D.C., Colombia

${ }^{5}$ Departamento de Biología Molecular, Instituto de Parasitología y Biomedicina López Neyra - CSIC, Parque Tecnológico de Ciencias de la Salud, Granada, España

${ }^{6}$ Centro de Investigaciones en Microbiología y Parasitología Tropical (CIMPAT), Universidad de los Andes, Bogotá, D.C., Colombia.

7 Grupo de Inmunobiología, Facultad de Ciencias, Pontificia Universidad Javeriana, Bogotá, D.C, Colombia.

Introducción. KMP-11 es una proteína conservada del Trypanosoma cruzi que se expresa en todos sus estadios. Su asociación con el citoesqueleto del parásito sugiere que contribuye a su movilidad y capacidad para invadir las células del huésped. El péptido K1, derivado de KMP-11, induce respuesta inmunitaria humoral y celular. Aunque se ha documentado la función protectora de los anticuerpos contra T. cruzi, pocos estudios han investigado el papel de los anticuerpos antígenoespecíficos. 
Materiales y métodos. Se obtuvo antisuero policlonal para $\mathrm{K} 1$ mediante la inmunización de dos conejos. Se inmunizó un conejo con un péptido humano no relacionado, como control de los ensayos. El potencial de reconocimiento del antisuero se evaluó mediante ELISA y Western blot frente a la KMP-11 recombinante (rKMP-11), y mediante inmunofluorescencia y citometría de flujo para la proteína nativa. La funcionalidad de los anticuerpos se evaluó en ensayos de invasión celular empleando células Vero y tripomastigotes.

Resultados. En ELISA solamente los sueros de los conejos inmunizados con $\mathrm{K} 1$ reconocieron al péptido y la proteína rKMP-11. La identificación de la rKMP-11 se confirmó por Western blot. La inmunofluorescencia indirecta mostró unión de los anticuerpos a la proteína nativa en los parásitos fijados, mientras que la citometría de flujo mostró unión a la proteína usando parásitos vivos. Los resultados fueron similares usando epimastigotes y tripomastigotes. En los ensayos de invasión se obtuvo una reducción significativa del número de parásitos intracelulares y el porcentaje de células infectadas cuando los tripomastigotes fueron preincubados con anticuerpos anti-K1.

Conclusiones. Se demostró que los anticuerpos policlonales anti-K1 fueron capaces de reconocer la proteína KMP-11 nativa de $T$. cruzi. Dichos anticuerpos redujeron la capacidad de invasión del parásito a las células mamíferas sensibles a la infección, probablemente bloqueando la motilidad del parásito más que la interacción entre moléculas parásito-célula.

$$
\text { - } \bullet
$$

\section{Partidores nucleares y del cinetoplasto en la detección de Trypanosoma cruzi mediante PCR en mujeres con enfermedad de Chagas y sus recién nacidos}

Macarena Leal, Inés Zulantay, Jessica Villamarín, Werner Apt

Laboratorio de Parasitología Básico-Clínico, Programa de Biología Celular y Molecular, ICBM, Facultad de Medicina, Universidad de Chile; Departamento de Salud, Municipalidad de Illapel, IV Región, Chile

Objetivo. Comparar la utilidad de partidores del cinetoplasto (k121-k122) y nucleares (nTc1-nTc2) para detectar Trypanosoma cruzi en el binomio madre-recién nacido.

Materiales y métodos. Se analizaron muestras de 40 binomios madres con enfermedad de Chagas/ recién nacidos procedentes de la provincia de
Choapa, IV Región, Chile, de quienes se extrajo sangre periférica antes del parto y del cordón umbilical al parto, respectivamente. Las madres se seleccionaron según la confirmación serológica para enfermedad de Chagas (IFI y ELISA IgG) establecida en el primer trimestre del embarazo. Se conformaron grupos según los resultados de la PCR del cinetoplasto (PCRk) de las madres previo al parto y se aplicó PCR con partidores nucleares (PCRn) a la totalidad de madres/recién nacido. Los resultados se analizaron mediante la prueba $Z$ y de McNemar de muestras asociadas con el programa SRSS®.

Resultados. En $82,5 \%$ de las muestras de madres con parasitemia positiva o negativa, al preparto con PCRk, PCRn fue positivo. En las madres negativas a PCRk, PCRn fue positivo en $65 \%$ de los casos. En los 40 recién nacidos, PCRk fue positivo en $7,5 \%$ de los casos, mientras que PCRn lo fue en $50 \%$. Dos casos congénitos, confirmados mediante serología convencional antes del año de vida, fueron positivos para ambos partidores, no obstante, los partidores nTc1-nTc2, detectaron en $42,5 \%$ de los recién nacidos, una banda de 166 pb que correspondería a trazas de ADN de $T$. cruzi, puesto que la serología de estos casos fue negativa en el seguimiento.

Conclusión. En ausencia de diagnóstico parasitológico directo en recién nacidos, la PCR es una alternativa para diagnosticar enfermedad de Chagas congénita. No obstante, este estudio confirma que el estudio serológico de los hijos de madres con enfermedad de Chagas mayores de 8 meses, es la estrategia más factible y recomendable de llevar a cabo en las zonas endémicas.

Financiamiento: Proyectos Fondecyt 1080445 y 1100768

\section{Xenodiagnóstico: la técnica de PCR en deyecciones de Triatoma infestans permitiría obviar la lectura microscópica}

Miguel Saavedra, Inés Zulantay, Werner Apt, Matías Molina, Sergio Ardiles, Juan Pablo Gálvez, Gabriela Martínez

Programa Biología Celular y Molecular, ICBM, Facultad de Medicina, Universidad de Chile; Hospital de Combarbalá, Departamento de Salud, Municipalidad de Canela; Departamento de Salud, Municipalidad de Salamanca; Servicio de Salud Coquimbo, IV Región, Chile

Objetivo. Comparar los resultados de la lectura microscópica del xenodiagnóstico aplicado en 
humanos con el PCR de deyecciones de Triatoma infestans (PCR-XD).

Materiales y métodos. A 120 pacientes con enfermedad de Chagas crónica, procedentes de la Provincia de Choapa, IV Región Chile, bajo consentimiento informado, se les aplicaron durante 20-30 minutos dos cajitas para xenodiagnóstico que contenía cada una 7 ninfas de tercer estadio de $T$. infestans. La lectura microscópica se realizó a los 30, 60 y 90 días de incubación de los triatominos en búsqueda de tripomastigotes móviles de $T$. cruzi. Las muestras de las deyecciones obtenidas en los tres períodos de incubación se mezclaron con solución tampón PBS, pH 7,2, se incubaron a $98 \stackrel{\circ}{\circ}$ por 15 minutos y se centrifugaron a $4.000 \mathrm{rpm}$ por 3 minutos. Se preparó un pool de los sobrenadantes y se extrajo el ADN mediante el kit Favorgen®. Para PCR-XD se utilizaron los partidores del cinetoplasto 121-122 que se alinean a las cuatro regiones constantes presentes en los minicírculos de $T$. cruzi, para obtener una banda de $330 \mathrm{pb}$. En todos los ensayos realizados por duplicado, se incluyeron controles de la reacción. La amplificación se realizó en termociclador TC 412. Los productos de amplificación se analizaron por electroforesis en gel de agarosa al $2 \%$ y se visualizaron por tinción con bromuro de etidio.

Resultados. De los 120 xenodiagnósticos evaluados, en 24 se observaron formas móviles de T. cruzi (20\%), mientras que PCR-XD fue positiva en 84 de ellos (70\%), incluyendo todos los casos xenodiagnóstico positivo

Conclusión. Se propone la eliminación de la etapa microscópica de lectura del xenodiagnóstico, lo que disminuiría el riesgo de contacto con formas infectantes de $T$. cruzi. El mayor rendimiento y precocidad de XD-PCR para detectar el parásito, constituye una ventaja de esta herramienta al aplicarla en el tratamiento de la enfermedad de Chagas.

Financiamiento: Proyectos Fondecyt 1100768 y 1080445

\section{Towards the establishment of a consensus Real-Time qPCR protocol to monitor Trypanosoma cruzi parasitaemia in chronic chagasic cardiomyopathy patients}

Otacilio Moreira' ${ }^{1,2}$, Juan David Ramírez ${ }^{3}$, Elsa

Velázquez ${ }^{4}$, Myllena Melo², Carolina L. Ferreira², Felipe Guhl $^{3}$, Sergio Sosa-Estani' ${ }^{4,5}$, Jose Antonio Marin-Neto ${ }^{6}$, Carlos A. Morillo7, Constança Britto²
1 Instituto Federal de Educação, Ciência e Tecnologia do Rio de Janeiro, Rio de Janeiro, Brasil

2 Laboratório de Biologia Molecular e Doenças Endêmicas, Instituto Oswaldo Cruz, FIOCRUZ, Rio de Janeiro, Brasil

3 Centro de Investigaciones en Microbiología y Parasitología Tropical, Universidad de los Andes, Bogotá, D.C., Colombia

4 Instituto Nacional de Chagas, Fatala Chaben, Buenos Aires, Argentina

5 Centro Nacional de Diagnóstico e Investigación de Endemoepidemias (CeNDIE) ANLIS Dr. Carlos G. Malbrán, Buenos Aires, Argentina

${ }^{6}$ Escola de Medicina de Ribeirão Preto, Universidade de São Paulo, Ribeirão Preto, São Paulo, Brasil

7 McMaster University, Population Health Research Institute HGH-McMaster Clinic, East Hamilton, Ontario, Canada

Introduction. Real-time PCR is an accurate method to quantify Trypanosoma cruzi DNA in clinical samples and can be used to followup specific chemotherapy in Chagas disease. Recently a qPCR workshop was held at FIOCRUZ/ $\mathrm{RJ}$ in order to generate a consensus protocol to be applied to the Benznidazole Evaluation for Interrupting Trypanosomiasis (BENEFIT) study, with the participation of 3 PCR Core Laboratories (Argentina, Brazil and Colombia). This report describes the evaluation of distinct DNA extraction procedures and $\mathrm{QPCR}$ protocols for the absolute quantification of $T$. cruzi DNA in Guanidine-EDTA blood lysates (GEB).

Materials and methods. Four primer sets directed to the conserved motifs within the repetitive $T$. cruzi satellite DNA sequence, and one targeted to the kDNA minicircles were compared in SYBR Green and TaqMan systems. Standard curve parameters, such as amplification efficiency, coefficient of determination and intercept were evaluated accordingly to the procedure used for obtaining DNA samples with known parasite concentrations. SYBR Green performance was assessed for each primer set to estimate parasitic load in six chronic chagasic cardiomyopathy (CCC) BENEFIT patients prior to drug/placebo administration.

Results and conclusions. The results suggested a more accurate quantification using the commercial kit based on silica-membrane technology, to enable efficient processing of GEB samples and to minimize sample contamination, comparing with the in-house phenol-chloroform method. Considering the complex profile revealed by kDNA melting curve analysis, the quantification data obtained with this primer set could not be precisely supported by SYBR Green. Regardless kDNA, 
all primers tested revealed good performance to quantify the parasitic load in CCC patients. The average $T$. cruzi DNA concentration from CCC patient triplicate samples varied from $0.02 \pm 0.01$ to $56.54 \pm 6.00$ parasites $/ \mathrm{mL}$, with 5 out of 6 patients presenting very scarce parasitaemia with less than 10 parasites $/ \mathrm{mL}$ of blood.

\section{Actividad antiparasitaria in vitro e in vivo y citotoxicidad de extractos de plantas de la familia Piperaceae contra Trypanosoma cruzi}

Paola García1, Manuel Sánchez-Moreno², Francisco

Olmo $^{2}$, Omar Triana ${ }^{1}$

1 Grupo Biología y Control de Enfermedades Infecciosas, Universidad de Antioquia, Medellín, Colombia

${ }^{2}$ Grupo Bioquímica y Parasitología Molecular, Universidad de Granada, Granada, España

Introducción. Los medicamentos disponibles para tratar la enfermedad de Chagas son escasos, poco efectivos y tóxicos. Las plantas se han utilizado como fuente de nuevas alternativas terapéuticas para enfermedades tropicales, como la enfermedad de Chagas.

El objetivo de este trabajo fue evaluar la actividad tripanocida in vitro e in vivo y la citotoxicidad de extractos y fracciones de plantas (Piperaceae) contra Trypanosoma cruzi.

Materiales y métodos. Se evaluaron extractos y fracciones de Piper marginatum, $P$. subpedale y $P$. sp. contra cepas humanas de $T$. cruzi y ensayos de citotoxicidad en células Vero, siguiendo la metodología MTT. Se seleccionaron las preparaciones promisorias, según los criterios de actividad, baja citotoxicidad y alta selectividad, para ser evaluadas en tripomastigotes y amastigotes, así como ensayos in vivo. Se realizaron, además pruebas de inhibición enzimática sobre la hierrosuperóxido dismutasa (Fe-SOD) del parásito y se analizaron por microscopía electrónica, como una aproximación a los mecanismos de acción de estos extractos.

Resultados. Los extractos totales mostraron resultados promisorios de actividad y baja citotoxicidad, sin embargo, las fracciones fueron más efectivas y altamente selectivas. La fracción 4, proveniente de la planta Piper sp., presentó una actividad de $14,29 \mu \mathrm{g} / \mathrm{ml}$ en epimastigotes y una citotoxicidad de $263,6 \mu \mathrm{g} / \mathrm{ml}$ en células Vero. Los índices de selectividad de esta fracción fueron $8,2,2,7$ y 2,1 en epimastigotes, amastigotes y tripomastigotes, respectivamente. Los ensayos in

vivo, fase aguda, mostraron que la fracción 4, a 30 $\mathrm{mg} / \mathrm{kg}$, reducía la parasitemia en $50 \%$ respecto al control, con mejores efectos que el benznidazol. Se encontró, además, que esta fracción inhibe alrededor de $60 \%$ la actividad de Fe-SOD y altera la membrana del parásito, genera formación de vacuolas y núcleos hinchados con cromatina condensada.

Conclusiones. Este estudio muestra que a partir de plantas se pueden obtener nuevos tratamientos para la enfermedad de Chagas. Se identificó una fracción con alto poder selectivo sobre el parásito.

-

\section{Pacientes con enfermedad de Chagas son capaces de responder frente a un antígeno heterólogo}

Paola Lasso ${ }^{1}$, Diana Mesa ${ }^{1}$, Natalia Bolaños ${ }^{2}$, Adriana Cuéllar ${ }^{3}$, Fanny Guzmán ${ }^{4}$, Zulma Cucunubá5, Fernando Rosas $^{6}$, Víctor Velasco ${ }^{6}$, María del Carmen Thomas ${ }^{7}$, Manuel Carlos López ${ }^{7}$, John Mario González², Concepción Judith Puerta ${ }^{1}$

1 Laboratorio de Parasitología Molecular, Pontificia Universidad Javeriana, Bogotá, D.C., Colombia

2 Grupo de Ciencias Básicas Médicas, Facultad de Medicina, Universidad de los Andes, Bogotá, D.C., Colombia

${ }^{3}$ Grupo de Inmunobiología y Biología Celular, Pontificia Universidad Javeriana, Bogotá, D.C., Colombia

4 Laboratorio de Genética e Inmunología Molecular, Universidad Católica de Valparaíso, Valparaíso, Chile

${ }^{5}$ Grupo de Parasitología, Instituto Nacional de Salud, Bogotá, D.C., Colombia

${ }^{6}$ Fundación Clínica Abood Shaio, Bogotá, D.C., Colombia

7 Instituto de Parasitología y Biomedicina López Neyra, CSIC, Granada, España

Introducción. El papel de los linfocitos T CD8 ${ }^{+}$ es crucial para el control de las infecciones intracelulares como en el caso de la infección por Trypanosoma cruzi. Cuando se evalúa la respuesta de los linfocitos $\mathrm{T} \mathrm{CD8}^{+}$frente a patógenos persistentes, se observa la pérdida jerárquica de funciones efectoras dando como resultado agotamiento clonal y disminución de linfocitos $T$ respondedores. Sin embargo, la capacidad de estos pacientes para responder a otros antígenos no se ha estudiado.

Con el objetivo de determinar si los pacientes con enfermedad de Chagas son inmunocompetentes frente a antígenos heterólogos, se evaluó en pacientes y controles sanos el fenotipo y la actividad funcional de los linfocitos T CD8 ${ }^{+}$específicos del virus de la influenza, con el cual la mayoría de los individuos han tenido contacto. 
Materiales y métodos. Se incluyeron 50 pacientes infectados con $T$. cruzi y 12 individuos negativos para la infección, quienes fueron tipificados para la molécula HLA-A*0201. Trece pacientes con enfermedad de Chagas y 5 individuos sanos resultaron HLA-A*0201+. Se incubaron células mononucleares de sangre periférica con el péptido MP-Flu* restringido al HLA-A*0201 derivado de la proteína matriz del virus y luego marcadas con el tetrámero HLA-A2-MP-Flu* y los anticuerpos para determinar su fenotipo y actividad funcional. Los datos se obtuvieron en un citómetro de flujo FACS Canto II y los análisis estadísticos se hicieron con el programa GraphPad Prism 3.0.

Resultados. Se encontraron células específicas para el péptido MP-Flu* en todos los pacientes con enfermedad de Chagas y en los individuos sanos sin diferencias significativas en las frecuencias halladas. En cuanto al fenotipo de los linfocitos $T$ específicos correspondió predominantemente a células de memoria efectora sin diferencias significativas entre pacientes y controles. La actividad funcional evaluada por la producción de IL-2, INF $\gamma$ CD107a/b y perforina fueron igualmente similares entre pacientes y controles.

Conclusiones. Estos resultados sugieren que aunque los pacientes con enfermedad de Chagas no logran el control de la infección por T. cruzi, son competentes al responder frente a otros antígenos.

$$
\bullet \bullet
$$

\section{Tetrahidro-1-benzoazepinas como posibles agentes tripanocidas}

Sandra Leal ${ }^{1}$, Carlos Mario Sanabria², Alirio Palma², Patricia Escobar ${ }^{1}$

1 Laboratorio de Quimioterapia, Centro de Investigación en Enfermedades Tropicales, Universidad Industrial de Santander, Bucaramanga, Colombia

2 Laboratorio de Síntesis Orgánica, Universidad Industrial de Santander, Bucaramanga, Colombia

Introducción. Una de las formas de transmisión de la enfermedad de Chagas, es por la transfusión. La violeta de genciana ha sido utilizada en algunos países de alta transmisión de la enfermedad como un agente profiláctico en unidades de sangre. Sin embargo, su toxicidad es cuestionable.

En este trabajo se reporta la actividad de una serie de derivados de la tetrahidro-1-benzoazepina contra las diferentes formas parasitarias de Trypanosoma cruzi, y en eritrocitos humanos y células Vero.

Metodología. Se evaluaron catorce derivados de la tetrahidro-1-benzoazepina, cuya característica estructural principal es que contienen en la posición C2 del anillo de la 1-benzazepina otro anillo de naftaleno o furano como sustituyente. Se trataron tripomastigotes, epimastigotes, y amastigotes intracelulares de $T$. cruzi (Sylvio $\mathrm{X} 10$ ), y eritrocitos y células Vero con diluciones seriadas de los compuestos, del medicamento de referencia nifurtimox y de violeta de genciana. La activad antiparasitaria se determinó por recuento microscópico y la citotoxicidad por MTT. Los resultados se expresaron en concentraciones inhibitorias 50 y $90\left(\mathrm{Cl}_{50}\right.$ y $\left.\mathrm{Cl}_{90}\right)$, obtenidas mediante regresión sigmoide.

Resultados. De los catorce compuestos evaluados, cinco (los derivados 1, 2, 3, 7 y 10) fueron activos contra epimastigotes $\left(\mathrm{Cl}_{50} 0,02-11,37 \mu \mathrm{M}\right)$ y uno (el derivado 10) en amastigotes intracelulares $\left(\mathrm{Cl}_{50}\right.$ $25,82 \mu \mathrm{M})$ de $T$. cruzi. Además, los compuestos 2,3 y 10 fueron activos en tripomastigotes $\left(\mathrm{Cl}_{50}\right.$ 2,55-11,23 $\mu \mathrm{M})$. Los tripomastigotes fueron menos sensibles a los compuestos que los epimastigotes. Ningún compuesto resultó ser tóxico contra eritrocitos $\left(\mathrm{Cl}_{50}>300 \mu \mathrm{M}\right)$, y el compuesto 1 fue tóxico en células Vero.

Conclusiones. La actividad de los derivados de la 1-benzoazepinas en tripomastigotes y su falta de toxicidad en eritrocitos sugiere que podrían constituir una opción como profilácticos en las unidades de sangre. El compuesto 10 mostró ser activo en las tres formas parasitarias evaluadas.

\section{Tratamiento de la enfermedad de Chagas crónica con nifurtimox, genotipificación de linajes de Trypanosoma cruzi}

Sylvia Ortiz, Aldo Solari, Juan Gaete, Cinthya Herrera, Valentina Ferrada, Jorge Rodríguez, Werner Apt, Inés Zulantay

Programa de Biología Celular y Molecular, ICBM, Escuela de Salud Pública, Facultad de Medicina, Universidad de Chile; Hospital de Los Vilos, Servicio de Salud Coquimbo, IV Región, Chile

Introducción. Trypanosoma cruzi ha sido clasificado en seis unidades discretas de tipificación, Tc $\mathrm{I}-\mathrm{VI}$, identificadas mediante técnicas moleculares, y las más frecuentes en Chile son Tcl, Tcll, TcV y TcVI.

Objetivo. Evaluar la permanencia y los linajes de T. cruzi presentes antes de la terapia con nifurtimox y después de ella en un grupo de pacientes con enfermedad de Chagas crónica.

Materiales y métodos. Se determinó mediante PCR la presencia de T. cruzien muestras de sangre (PCR-S) y xenodiagnóstico (PCR-XD) tomadas 
antes de la terapia con nifurtimox y después de ella.

Los resultados obtenidos antes de la terapia son diferentes a los de después de la terapia con nifurtimox lo que indica que el tratamiento parece ser efectivo durante el seguimiento reciente $(p \leq 0,0001)$. En una muestraseleccionada, se realizó genotipificación de los linajes infectantes mediante el uso de un set de sondas que permite identificar los genotipos más frecuentes en Chile, a partir de ADN purificado desde sangre y xenodiagnóstico. Los genotipos más frecuentes fueron TcV para sangre y Tcl para xenodiagnóstico antes de la terapia. Después de la terapia, Tcl parece ser el más resistente al fármaco en comparación con los otros linajes identificados. Los resultados obtenidos sugieren que la mayoría de los sujetos del estudio se encuentran infectados primordialmente con una combinación de tres linajes de T. cruzi (Tcl, Tcll y TcV).

Conclusión. Existe una reducción de la parasitemia en los controles después de la terapia reciente con infecciones que mayoritariamente corresponden a mezclas de linajes.

Financiamiento: Proyectos Fondecyt 1100768 y 1080445 


\section{Enfermedad de Chagas}

\section{ENTOMOLOGÍA}

\section{Diferenciación de poblaciones de Triatoma dimidiata capitata (Hemiptera: Reduvidae: Triatominae) de Colombia y su relación con la evolución molecular del complejo críptico dimidiata}

Andrés Gómez-Palacio ${ }^{1}$, Paula Marcet ${ }^{2}$, Nicolás Jaramillo-Ocampo ${ }^{1}$, Gabriel Parra-Henao ${ }^{3}$, Víctor Angulo $^{4}$, Ellen Dotson ${ }^{2}$, Omar Triana ${ }^{1}$

1 Grupo de Biología y Control de Enfermedades Infecciosas, Universidad de Antioquia, Medellin, Colombia.

2 Division of Parasitic Diseases and Malaria, Entomology Branch, Centers for Disease Control and Prevention, Atlanta, GA, USA

3 Instituto Colombiano de Medicina Tropical, Universidad CES, Medellín, Colombia

${ }^{4}$ Centro de Investigaciones en Enfermedades Tropicales, Universidad Industrial de Santander, Bucaramanga, Colombia

Introducción. Triatoma dimidiata capitata en Colombia muestra una importante diversidad ecoepidemiológica a lo largo de su distribución. A pesar de la relevancia que representa, existe escaso conocimiento sobre su estructura y dinámicas de población, y de su relación con la actual hipótesis filogeográfica. Este desconocimiento fue abordado mediante el análisis genético de distintas poblaciones representativas de su distribución en Colombia.

Materiales y métodos. Se analizaron 250 insectos de 11 departamentos. Los análisis de poblaciones incluyeron 10 locimicrosatélites y secuencias de los genes mitocondriales ND4 y CO1, y del ITS-2. Se estimó el polimorfismo y la diversidad génica, y un análisis de estructuración y mezcla de poblaciones. Se hizo una caracterización cromosómica, y un análisis filogenético incluyendo sus congéneres centroamericanos.

Resultados. El análisis por microsatélites y secuencias mostró un alto grado de diversidad y una clara diferenciación, coherente con un aislamiento geográfico de las poblaciones de los valles interandinos, la llanura del Caribe y la Sierra Nevada de Santa Marta. Asimismo, el análisis intrapoblación sugirió un alto grado de mezcla génica entre los aislamientos extradomiciliarios y los intradomiciliarios en los valles interandinos, pero no en el Caribe, debido a una moderada subestructuración. Se corroboró el citotipo, y el análisis filogenético, tanto para el ITS-2 como para el ND4, no sustentó la posición filogenética propuesta para las poblaciones colombianas con respecto a sus congéneres centroamericanos.

Conclusiones. Se identifica una estructura de poblaciones de $T$. dimidiata en Colombia coherente con un modelo de aislamiento por distancia geográfica. El grado de mezcla entre aislamientos extradomiciliarios e intradomiciliarios en la Región Andina llama la atención sobre las posibles consecuencias de la fallo en el control. La diversidad y la estructura detectada impiden corroborar la filogenética de las tres subespecies continentales propuestas. Esto sugiere que un mayor esfuerzo de análisis de la diversidad y diferenciación de las subespecies centroamericanas debe aún ser evaluado.

$$
\text { - } \bullet
$$

\section{Infestación por Trypanosoma cruzi de triatominos en General Villamil Playas, provincia del Guayas, Ecuador}

Ángel Guevara, Yosselin Vicuña, Fernanda Jiménez, Leonardo Quinde, José Prado

Laboratorio de Parasitología Molecular, Centro de Biomedicina, Universidad Central del Ecuador, Quito, Ecuador

Escuela Politécnica del Ejército ESPE, Carrera de Ingeniería en Biotecnología, Campus Sangolquí,

Ecuador

SNEM-MSP, Guayaquil, Ecuador

Introducción. La enfermedad de Chagas fue descrita en Ecuador desde 1929. Datos recientes revelan que $61 \%$ de la población del país habita en áreas con presencia de vectores de Trypanosoma cruzi. En Ecuador, Triatoma dimidiata y Rhodnius ecuadoriensis son los vectores más importantes en Ecuador y están en marcha programas de control con insecticidas residuales para eliminar los vectores.

En el presente trabajo se estudiaron las poblaciones vectoriales involucradas en el ciclo de vida del parásito $T$. cruzi en General Villamil Playas, provincia de Guayas, Ecuador.

Materiales y métodos. La recolección de triatomas se realizó mediante búsqueda activa; se determinó el nivel de infestación por $T$. cruzi 
microscópicamente en el contenido fecal de los triatomas; el contenido fecal de algunos triatomas positivos se inoculó en animales de laboratorio. En uno de los sitios de recolección se capturó un reservorio marsupial silvestre para detectar infección natural por T. cruzi.

Resultados. Se recolectaron 1.018 triatomas, identificados como $T$. dimidiata, se analizaron 594 y se identificaron 585 (98,48\%) infestados por $T$. cruzi. Los ratones BALB/c inoculados con heces de triatomas infestados por $T$. cruzi no demostraron parasitemia pero fueron positivos por PCR y pruebas serológicas. El reservorio silvestre capturado identificado como Didelphis marsupialis, fue positivo para infección por T. cruzi.

Conclusiones. El estudio demuestra una alta presencia de un vector único para $T$. cruzi, $T$. dimidiata, en General Villamil Playas. El elevado porcentaje de triatomas infestados (98,48 \%) sugiere alto riesgo de infección para humanos ya que los sitios donde se encontraron los triatomas son urbanos. La presencia de reservorios silvestres $D$. marsupialis positivo para infección natural por $T$. cruzi podría indicar que la infección está en ciclo silvestre. Estudios epidemiológicos en humanos para determinar la prevalencia de la infección por $T$. cruzi están en marcha y dado que en esta población existe solamente Triatoma dimidiata, el control mediante insecticidas o biológico es factible.

Con el auspicio de Consejo Superior de Investigaciones Científicas de España y proyecto RedTrV (CYTED 209RT0364).

Nota: parte de este estudio fue presentado en el "I Iberoamerican Workshop on Chagas Disease, Triatomine vectors, T. cruzi, and triatoma virus"; Centro de Malária e Outras Doenças Tropicais (UCDT/CMDT), Instituto de Higiene e Medicina Tropical, Lisboa, Portugal.

\section{Los linajes filogenéticos del género Rhodnius transmiten genotipos diferentes de Trypanosoma rangeli lo cual indica una posible relación coevolutiva entre los parásitos y los vectores}

Daniel Alfonso Urrea ${ }^{1}$, Felipe Guhl², Claudia Patricia Herrera $^{2}$, Alejandra Falla ${ }^{2}$, Julio César Carranza ${ }^{1}$, César Cuba-Cuba ${ }^{3}$, Omar Triana-Chávez ${ }^{4}$, Edmundo C. Grisard $^{5}$, Gustavo Adolfo Vallejo

${ }^{1}$ Laboratorio de Investigaciones en Parasitología Tropical, Universidad del Tolima, Ibagué, Colombia

${ }^{2}$ Centro de Investigaciones en Microbiología y
Parasitología Tropical, Universidad de los Andes, Bogotá, D.C., Colombia

${ }^{3}$ Laboratorio de Parasitologia Médica e Biologia de Vetores, Faculdade de Medicina, Área de Patologia, Universidade de Brasilia, Brasilia, Brasil

${ }^{4}$ Instituto de Biología, Universidad de Antioquia, Medellín, Colombia

${ }^{5}$ Departamento de Microbiologia, Imunologia e Parasitologia, Universidade Federal de Santa Catarina, santa Catarina, Brasil

Introducción. Varios genotipos de Trypanosoma rangeli se distribuyen desde Centroamérica hasta el sur de Brasil, transmitidos por, al menos, 16 especies de Rhodnius, las cuales están agrupadas en dos linajes filogenéticos: el linaje "pictipes", de la región transandina y el linaje "robustus" de origen cis-andino.

Objetivo. Explorar la utilidad de la región intergénica de Spliced Leader (SL-IR) en la genotipificación de $T$. rangeli aislado de Rhodnius prolixus, $R$. pallescens II, $R$. colombiensis y $R$. ecuadoriensis II, para evaluar una posible asociación entre los genotipos y los linajes filogenéticos de Rhodnius.

Materiales y métodos. Seanalizaron 34 secuencias del SL-IR de T. rangeli, con las cuales se evaluó la presencia de STR, SNP y la reconstrucción filogenética para la identificación de genotipos. La consistencia en los dendrogramas se valoró por comparación con perfiles de RAPD.

Resultados. Las cepas aisladas del mismo vector 0 de vertebrados en áreas de distribución del vector, presentaron el mismo genotipo aun en cepas aisladas en regiones geográficamente distantes. El alineamiento de secuencias permitió identificar los siguientes genotipos de $T$. rangeli:

Genotipo robustus: conformado por cepas de $T$. rangeli aisladas de $R$. prolixus y $R$. robustus (linaje "robustus"), al oriente de la cordillera de los Andes en Colombia, Venezuela y Brasil.

Genotipo pallescens II: constituido por cepas aisladas de $R$. pallescens II (linaje "pictipes") en el noroccidente y en el centro de Colombia.

Genotipo colombiensis: compuesto por cepas aisladas de $R$. colombiensis (linaje "pictipes") en el sur del valle del río Magdalena (Colombia).

Genotipo ecuadoriensis II: formado por cepas aisladas de $R$. ecuadoriensis (linaje "pictipes") en el norte del Perú.

Conclusiones. Estos resultados confirman una asociación entre genotipos de $T$. rangeli y los linajes filogenéticos de sus vectores, la cual demuestra el papel determinante de los vectores en la distribución geográfica de los genotipos del parásito. 


\section{Registros electrofisiológicos en ojos compuestos de Rhodnius prolixus (Heteroptera: Reduviidae)}

Edwin Hincapié-Peñaloza, Jorge Molina

Centro de investigaciones en Microbiología y

Parasitología Tropical, Universidad de los Andes,

Bogotá, D.C., Colombia

Introducción. Rhodnius prolixus es el vector más importante de Trypanosoma cruzi en el norte de Suramérica. Diversos estudios del comportamiento en el laboratorio y en el campo han demostrado el papel importante de los estímulos lumínicos en el proceso de infestación de viviendas. Sin embargo, no existen registros electrofisiológicos que evalúen el efecto de la luz sobre el ojo compuesto de este insecto.

Materiales y métodos. Mediante electrorretinogramas tomados a diferentes horas del día, investigamos la respuesta de los ojos compuestos de $R$. prolixus a estímulos de 100 ms de duración con luz blanca (picos en 450 y $560 \mathrm{~nm}$ y $4,41 \mu \mathrm{W} /$ $\mathrm{cm}^{2}$ de intensidad) y adaptados a la oscuridad. Todos los experimentos se llevaron a cabo a $22{ }^{\circ} \mathrm{C}$. La respuesta fue evaluada como la amplitud en la diferencia de voltaje entre el electrodo del ojo compuesto y un electrodo indiferente en el abdomen.

Resultados. Las respuestas encontradas fueron registradas con $\pm 50 \mathrm{~ms}$ de latencia y mostraron que el tiempo de adaptación a la oscuridad no influye sobre las mediciones. Se encontraron, además, diferencias significativas en las respuestas electrofisiológicas de hembras y machos realizadas a la misma hora del día. Finalmente, las comparaciones entre la fotofase y la escotofase en ambos sexos no permitieron establecer diferencias en las respuestas electrofisiológicas.

Conclusiones. Este primer trabajo con electrorretinogramas permitió determinar la influencia del sexo y del ritmo circadiano sobre las respuestas electrofisiológicas en $R$. prolixus. Estos resultados nos permitirán entender mejor el papel de la luz artificial en la respuesta del sistema visual de $R$. prolixus.

\section{Herramienta para la realización de electrorretinogramas en ojos compuestos de insectos vectores de la enfermedad de Chagas (Triatominae: Heteroptera: Reduviidae)}

Edwin Hincapié-Peñaloza1, Maritza Torres ${ }^{1}$, David Guzmán², Javier Carreño$^{3}$, Jorge Molina ${ }^{1}$
1 Centro de investigaciones en Microbiología y Parasitología Tropical, Universidad de los Andes, Bogotá, D.C., Colombia.

2 Departamento de Física, Universidad de los Andes, Bogotá, D.C., Colombia.

${ }^{3}$ Laboratorio de Botánica y Sistemática, Universidad de los Andes, Bogotá, D.C., Colombia.

Introducción. Algunos especies de la subfamilia Triatominae son vectores importantes de Trypanosoma cruzi y los estudios de comportamiento han demostrado que los estímulos lumínicos juegan un papel importante en el proceso de infestación de viviendas. Sin embargo, no se ha desarrollado una herramienta que permita realizar electrorretinogramas para evaluar el efecto de la luz sobre el ojo compuesto de estos insectos.

Materiales y métodos. Las unidades que conforman esta herramienta son:

- un sistema que garantiza la fijación, el montaje y la manipulación del insecto en los ejes X, Y y Z;

- un sistema electrónico a base de integrados LM555 que permite la producción de estímulos lumínicos de diferente intensidad y tiempo los cuales son revelados a través de LEDES insertados en un tambor que al ser rotado enfoca la luz sobre la cabeza del insecto; la luz del LED es llevada exactamente sobre el ojo compuesto por medio de un espejo en forma de embudo;

- electrodos conformados por jeringas de $1 \mathrm{~cm}^{3}$, capilares de vidrio, solución salina y alambres de plata conectados a cables VNC, que conducen las señales eléctricas desde el insecto hasta el amplificador; el electrodo de grabación se coloca sobre la superficie del ojo compuesto y el mejor lugar para la inserción del electrodo de referencia es la parte anterior dorsal del abdomen del insecto;

- las luces de diferente espectro para la adaptación selectiva son generadas por LEDES que están ubicados sobre el insecto y controlados por -un sistema electrónico negador que permite proporcionar luz de adaptación mientras el estímulo esté apagado.

Las anteriores unidades están dentro de una caja de madera (15 x 12 × $15 \mathrm{~cm}$.) fácilmente desarmable, pintada de color negro mate y recubierta de malla metálica con conexión a tierra que aísla el experimento de la radiación electromagnética circundante.

Resultados. Esta herramienta nos permitió registrar la actividad de la retina en triatominos, y podemos llegar a determinar las longitudes de onda e intensidades a las cuales son más sensibles los ojos compuestos de estos insectos. 
Conclusiones. Esta herramienta permitirá entender mejor el papel de la luz artificial en la respuesta del sistema visual de los Triatominae.

$$
\text { - } \bullet
$$

\section{La luz artificial incrementa la infestación de las casas por Triatoma dimidiata en la península de Yucatán, México}

Freddy Pacheco-Tucuch, María Jesús Ramírez-Sierra, Sebastien Gourbiere, Eric Dumonteil

Laboratorio de Parasitología, CIR, Universidad

Autónoma de Yucatán, Mérida, México

Introducción. Triatoma dimidiata es uno de los principales vectores de la enfermedad de Chagas en el sureste de México y documentamos en estudios anteriores que invade de manera estacional las viviendas humanas en la península de Yucatán. Demostramos, también, que los insectos son atraídos a las casas, pero no se han identificados los factores responsables de esta atracción. Es bien conocido que la luz artificial atrae a muchos triatominos y se utilizan frecuentemente trampas de luz para la recolección de insectos silvestres. Varios autores han también postulado que la luz puede atraer a triatominos en las casas, pero el papel de la luz artificial en la infestación de las casas no ha sido evaluado en detalle.

Materiales y métodos. Analizamos la distribución especial de las luces artificiales y de las casas infestadas en tres localidades rurales del estado de Yucatán. También, se realizaron experimentos conductuales en una caja de doble elección para evaluar con mayor detalle el comportamiento de $T$. dimidiata frente a la luz.

Resultados. En las tres localidades, las casas infestadas se ubican más cerca de las fuentes de luces artificiales que las casas que no están infestadas y las luces publicas se asociaron más con la infestación que las luces de los peridomicilios. Así, una casa próxima a una luz pública tiene una probabilidad 2,72 mayor de ser infestada (OR, $I_{95 \%}$ 2,04-3,61). Los experimentos conductuales confirmaron que los adultos de $T$. dimidiata están atraídos por la luz durante su actividad nocturna, y, en menor grado, las ninfas de quinto estadio.

Conclusiones. Si bien el alumbramiento público se asocia generalmente con el desarrollo de las localidades, nuestros datos indican que puede también contribuir a la infestación de las casas por T. dimidiata.

\section{Persistencia de la infestación} con triatominos en comunidades previamente tratadas con deltametrina en el sur de Ecuador

Mario J. Grijalva ${ }^{1,2}$, Anita G. Villacis ${ }^{2}$

1 Tropical Disease Institute, Biomedical Sciences Department, Heritage College of Osteopathic Medicine, Ohio University, Athens, OH, USA

2 Centro de Investigación en Enfermedades Infecciosas, Escuela de Biología, Pontificia

Universidad Católica del Ecuador, Quito, Ecuador

Introducción. La enfermedad de Chagas es considerada endémica en los valles temperados de la región sur de los Andes del Ecuador. Las principales especies de vectores de Trypanosoma cruzi en esta región son Rhodnius ecuadoriensis, Triatoma carrioni, Panstrongylus chinai y $P$. rufotuberculatus.

La meta de este estudio fue describir la infestación actual con triatominos en dos comunidades que, en el 2008 y 2010, recibieron rociamiento selectivo con deltametrina en todas las viviendas que fueron encontradas infestadas con triatominos.

Materiales y métodos. Las búsquedas manuales se realizaron en el domicilio y en el peridomicilio de todas las viviendas mediante el método de una hora/hombre en las comunidades Chaquizca y Guara, del cantón Calvas, Provincia de Loja.

Resultados. Se recolectaron 272 triatominos vivos ( $R$. ecuadoriensis y $P$. chinal) infestando 34 $\%$ y $15 \%$ de viviendas en Chaquizca y Guara, respectivamente. Se encontraron ninfas en $90 \%$ de los domicilios infestados.

Conclusiones. Estos resultados demuestran que se deben utilizar los métodos alternativos de control, que incluyen el mejoramiento de las viviendas y un sistema comunitario de vigilancia entomológica, para complementar el control vectorial utilizando insecticidas con el fin de lograr el control a largo plazo de la transmisión de Chagas en esta región.

\section{Riesgo de transmisión urbana de Trypanosoma cruzi por Panstrongylus geniculatus}

Juan Carlos Londoño1,2, Lucelia Briceño1, Hernán

Carrasco ${ }^{1,}$, Marlene Rodríguez ${ }^{1}$

1 Laboratorio de Biología Molecular de Protozoarios, Instituto de Medicina Tropical, Universidad Central de Venezuela, Caracas, Venezuela

2 Posgrado en Zoología, Universidad Central de

Venezuela, Caracas, Venezuela

Introducción. El presente estudio se realizó con el objetivo de determinar la presencia de 
diferentes especies de triatominos en el interior y el peridomicilio de las viviendas del área metropolitana de Caracas, su infección natural por Trypanosoma cruzi y el riesgo de transmisión de este parásito por el triatomino de mayor ocurrencia en la ciudad.

Materiales y métodos. Se evaluaron 1.967 triatominos durante el periodo enero-diciembre de 2010. La determinación de la infección natural por $T$. cruzise realizó por medio del examen parasitológico directo de los triatominos. Se utilizó la información sobre la ingestión de sangre de una submuestra de Panstrongylus geniculatus $(n=89)$ para calcular el odds ratio (OR) como un indicador indirecto del riesgo de picadura por parte de esta especie.

Resultados. El $53 \%$ de los triatominos se encontraron naturalmente infectados con $T$. cruzi. Panstrongylus geniculatus fue la especie de triatomino hallada con mayor frecuencia en el interior o en el peridomicilio de las viviendas $(95,3$ $\%)$. La presencia de sangre en el contenido intestinal de la muestra seleccionada de $P$. geniculatus fue de $39,3 \%$. El odds ratio muestra que cuando el factor de exposición corresponde a $P$. geniculatus hembra, el OR es de 10,2, y cuando el factor de exposición corresponde a machos, entonces el OR es de 0,2424.

Conclusiones. Panstrongylus geniculatus es el triatomino hallado con mayor frecuencia en el interior y en el peridomicilio de las viviendas del área metropolitana de Caracas. Este hecho, sumado a la alta tasa de infección natural por $T$. cruzi, incrementa la probabilidad de contacto entre el vector y la población humana o de animales domésticos y sinantrópicos, lo que posibilita la instauración y el mantenimiento del ciclo biológico del parásito a nivel urbano. El valor del OR indica que las hembras de $P$. geniculatus representan un mayor riesgo de picadura ya sea para el hombre o para los animales domésticos.

\section{- $\bullet$}

Phylogeography of the Chagas disease vector Rhodnius nasutus (Hemiptera: Reduviidae) in the Caatinga biome

Marcio G. Pavan'1, Rodrigo Gurgel-Gonçalves², Jessica

C. Antonio ${ }^{1}$, Karina A. Morelli ${ }^{1}$, Marli M. Lima ${ }^{3}$, Fernando

A. Monteiro ${ }^{1}$

${ }^{1}$ Laboratório de Biologia Molecular de

Microorganismos, Instituto Oswaldo Cruz, Rio de Janeiro, Brasil

2 Laboratório de Parasitologia e Biologia de Vetores, Universidade de Brasília, Brasilia, D.F., Brasil

3 Laboratório de Ecoepidemiologia da Doença de

Chagas, Instituto Oswaldo Cruz, Rio de Janeiro, Brasil
Introduction. Nowadays, vectorial Chagas disease transmission in Latin America occurs mainly due to the reinfestation of insecticide-treated households by sylvatic native vectors. All Rhodnius spp., which have succeeded in the colonization of artificial environments, derive from ancestral stocks that were adapted to arid or semiarid climates. Rhodnius nasutus and the Caatinga biome serve as a good example. The study of its origin, dispersion and genetic variability will shed light on the historical colonization processes that took place in this biome. Additionally, this investigation could pinpoint which populations are able to colonize and become adapted to different microhabitats, and thus, aid in fine-scale epidemiological surveillance.

Materials and methods. One hundred and forty-six insects collected in eight sites from five states of northeastern Brazil and morphologically identified as $R$. nasutus were sequenced for a $559 \mathrm{pb}$ fragment of the mitochondrial cytochrome $b$ gene, and compared with other sequences from specimens that belong to the ' $R$. prolixus group' (R.prolixus, $R$. robustus I-IV, and $R$. neglectus) for alpha-taxonomy. Phylogeographic and population genetics analyses were done in order to advance our understanding about the origin and dispersion of the species in the Caatinga biome.

Results. Rhodnius nasutus represents a monophyletic species that diverged from the ' $R$. prolixus group' of species during Middle/Late Miocene ( 11 Mya). It seems that the Caatinga biome was occupied first, during Early Pleistocene. At this same period, ancestral populations of $R$. nasutus (probably localized at Jaguaruana, Ceará) suffered local extinctions, followed by a range of demographic and spatial expansion during glacial periods, when populations of the drier Caatinga areas extended into the Cerrado. There seems to be little contemporary gene flow among the eight detected populations $\left(\mathrm{F}_{\mathrm{ST}} \geq 0.7\right)$.

Conclusions. The implementation of an evolutionary perspective through phylogeographic analyses furthers our knowledge on the origin and dispersion of $R$. nasutus, and helps clarify its present day distribution in the Caatinga and Cerrado biomes.

\section{Distribución de triatominos} (Hemiptera: Reduviidae) en dos comunidades indígenas de la Sierra Nevada de Santa Marta, Colombia

María Teresa Mojicaํ, Jorge Armando Egurrola', Duámaco Escribano², Juan Carlos Dib²

1 Centro de Investigación en Medicina Tropical, 
Universidad del Magdalena, Santa Marta, Colombia

2 Centro de Investigación en Enfermedades Tropicales, Fundación Salud para el Trópico, Santa Marta, Colombia

Introducción. La enfermedad de Chagas en la Sierra Nevada de Santa Marta es una parasitosis altamente endémica. Este estudio se realizó con el objetivo de determinar la distribución de los triatominos vectores de la enfermedad de Chagas en dos comunidades indígenas de la Sierra Nevada de Santa Marta.

Materiales y métodos. Se realizó la caracterización, inspección y captura manual en intradomicilio y peridomicilio a razón de hombre/hora/casa; se calcularon los índices entomológicos en las comunidades indígenas de Gomake (cuenca del río Jeréz) y Umandita (cuenca del río Palomino).

Resultados. Se inspeccionaron 50 viviendas en Umandita y 55 en Gomake, donde se encontraron 216 triatominos (96 ninfas y 120 adultos), 54 en Umandita y 162 en Gomake. Las especies encontradas fueron Rhodnuis prolixus (91,2 $\%)$ y Triatoma dimidiata $(7,8 \%) ; 11$ triatominos resultaron positivos para Trypanosoma cruzi, 2 provenientes de Umandita y 9 de Gomake. Los vectores se hallaron con mayor frecuencia en la pared, el suelo y la cama. Los gallineros fueron el ambiente peridoméstico donde se recolectó el mayor número de triatominos en las fincas. Los índices entomológicos muestran que Rhodnius prolixus registró mayor dispersión y mayor valor de infección con $T$. cruzi (5\%) para las dos comunidades. El índice de infestación domiciliaria fue de $16 \%$ para Umandita y de 34,5\% para Gomake; el índice de dispersión fue mayor en Gomake con 20,4 \% que en Umandita, 10,7 \%.

Conclusión. Las características del ambiente, el material de las viviendas y la disponibilidad de alimento, facilitan la domiciliación del $R$. prolixus, sumado a la seroprevalencia de la enfermedad de Chagas de 14,05 $\%$ en Umandita y de 32,24\% en Gomake (resultados obtenidos para el mismo periodo de tiempo), que aumentan la probabilidad de infección y se evidencia la transmisión activa de T. cruzi.

Financiado por Colciencias, contrato 308-2007.

Efecto del estado nutricional de Rhodnius prolixus sobre la atracción de sus heces y de una mezcla de compuestos volátiles presentes en el sudor humano

Mario Ortiz, Jorge Molina
Centro de Investigaciones en Microbiología y

Parasitología Tropical, Universidad de los Andes, Bogotá, D.C., Colombia.

Introducción. El comportamiento de Rhodnius prolixus está influenciado por diferentes semioquímicos. Entre éstos se encuentran las feromonas de agregación presentes en las heces y las cairomonas producidas por el huésped.

El objetivo del trabajo fue establecer en el laboratorio y a nivel de comportamiento, el efecto del estado nutricional del insecto sobre la atracción de estímulos relevantes en el comportamiento de búsqueda del huésped.

Materiales y métodos. Se utilizó un olfatómetro de decisión dual en forma de $\mathrm{T}$ para los ensayos. En cada ensayo se utilizaron 40 insectos, 20 machos y 20 hembras, con diferentes estados nutricionales (15 días sin alimentar y recién alimentados). Inicialmente, se realizó un ensayo control sin estímulo a ambos lados y luego se evaluó el efecto de atración de una mezcla de compuestos volátiles del sudor humano en uno de los lados. Se evaluaron $R$. prolixus sin alimentar utilizando como estímulos la mezcla de compuestos volátiles y, simultáneamente, las heces del insecto. Finalmente, la atracción de ambos estímulos se evaluó simultáneamente también en insectos recién alimentados. Los resultados del olfatómetro se analizaron mediante pruebas binomiales y las diferencias entre machos y hembras fueron evaluadas por medio de la pruebe de ji al cuadrado.

Resultados. No se encontraron diferencias entre machos y hembras ( $X^{2}$ no significativo). El control arrojó una distribución aleatoria $(p>0,05)$ mientras que la mezcla demostró ser altamente atractiva para $R$. prolixus $(p<0,05)$. Rhodnius prolixus sin alimentartambiénfueronatraídossignificativamente por la mezcla $(p<0,05)$ mientras que los recién alimentados fueron atraídos significativamente por las heces $(p<0,05)$.

Conclusiones. El estado nutricional de $R$. prolixus tiene un efecto importante sobre el comportamiento inducido por las cairomonas humanas y por las feromonas de agregación. Los insectos sin alimentar son atraídos por las cairomonas del huésped y no por las heces, mientras que aquellos alimentados son atraídos por las heces y no por las cairomonas. 


\section{Intrusión de Pastrongylus geniculatus y Rhodnius pallescens a viviendas y áreas sociales en un barrio de Bucaramanga, Santander, Colombia}

Marlene Reyes ${ }^{1}$, Lyda Esteban1, Flor Ángela Torres ${ }^{1,2}$, Mónica Flórez¹, Juan Carlos Agudelo¹, Víctor Manuel

Angulo $^{1}$

1 Centro de Investigaciones en Enfermedades

Tropicales, Universidad Industrial de Santander, Bucaramanga, Colombia

2 Ciencias Básicas Biomédicas, Universidad Industrial de Santander, Bucaramanga, Colombia

Introducción. La frecuente presencia de triatominos en las viviendas y en áreas comunes de recreo en los barrios del área metropolitana de Bucaramanga motivó, la realización del presente estudio, con el fin de establecer la intrusión de especies de triatominos en el barrio Villa del Prado ubicado en la periferia de la escarpa que rodea la ciudad.

Metodología. Con la participación de la comunidad para la recolección y la utilización de trampas de luz (Shannon), trampas con cebo animal (Angulo y Noireau) y recolección manual en el alumbrado público, se realizó captura de triatominos durante tres días cada mes por seis meses, en viviendas, bosque periférico, canchas de basquetbol y microfútbol, y parqueadero iluminados durante la noche. Los insectos recolectados fueron determinados por la clave de Lent y Wygodzinski (1979) y sus heces examinadas para determinar la presencia de tripanosomas.

Resultados. Se recolectaron 4 Panstrongylus geniculatus en la cancha, 3 en viviendas y 1 en el bosque, y 6 Rhodnius pallescens en la cancha y el parqueadero y 3 en viviendas y 2 en el bosque. El mayor número de triatominos fue recolectado por la comunidad. Se reconocieron tripanosomas por examen directo de heces, $50 \%(3 / 6)$ en $P$. geniculatus y $60 \%(3 / 5)$ en $R$. pallescens.

Conclusiones. El hallazgo y la captura en áreas urbanas de especies silvestres infectadas con tripanosomas y encontradas en viviendas en los recientes brotes de Chagas agudo en Santander, demuestran el riesgo al cual están sometidas estas poblaciones humanas, y la necesidad de caracterizar los nuevos condiciones de transmisión de la enfermedad de Chagas en Colombia para el diseño de estrategias de control adecuados.

Financiación. Colciencias COD: 110249326216 y Secretaría de Salud de Santander.

\section{Distribución de vectores de la enfermedad de Chagas en Cundinamarca, Colombia}

Néstor Pinto ${ }^{1}$, Claribell Hernández ${ }^{1}$, Patricia Fuya ${ }^{1}$, Pilar Carrillo ${ }^{1}$, Fernando Sánchez ${ }^{2}$

${ }^{1}$ Unidad de Entomología, Laboratorio de Salud Pública de Cundinamarca, Bogotá, D,C., Colombia

2 Programa de Enfermedades Transmitidas por Vectores, Secretaría de Salud de Cundinamarca, Bogotá, D,C., Colombia

Introducción. El departamento de Cundinamarca cuenta con 68 municipios en riesgo para la transmisión vectorial de la enfermedad de Chagas. De acuerdo con los resultados del programa nacional de promoción y prevención de esta enfermedad, 11 municipios son de alto riesgo, 8 de mediano y 49 de bajo. La Secretaría de Salud de Cundinamarca viene realizando el control de los triatominos, con base en los resultados de la vigilancia entomológica.

Objetivo. El objetivo de este trabajo fue dar a conocer la distribución actualizada de los triatominos en el departamento de Cundinamarca, información que permite orientar las acciones de prevención y control del vector.

Materiales y métodos. La búsqueda de triatominos es una actividad regular desarrollada por los técnicos del Programa de Enfermedades Transmitidas por Vectores, bajo la supervisión de los entomólogos del Laboratorio de Salud Pública. La recolección se realiza en forma manual, y los triatominos se envían al laboratorio para la confirmación taxonómica hasta especie. Las actividades de vigilancia se realizan en las localidades rurales consideradas como áreas de riesgo.

Resultados. En el periodo comprendido entre el 2000 y el 2011 se han recolectado 2.223 triatominos en 366 localidades de 34 municipios. Se reportan 10 especies de triatominos Rhodnius prolixus (16 municipios), $R$. colombiensis (14 municipios), $R$. pallescens (13 municipios), $R$. pictipes (2 municipios), $R$. robustus (1 municipio), Triatoma venosa (10 municipios), T. dimidiata (1 municipio), Panstrongylus geniculatus (26 municipios), $P$. lignarius (1 municipio), $P$. rufotuberculatus (6 municipios) y Eratyrus mucronatus (2 municipios). Conclusión. En Cundinamarca circulan 10 especies de triatominos, $P$. geniculatus es la especie de mayor distribución, seguida por Rhodnius prolixus.
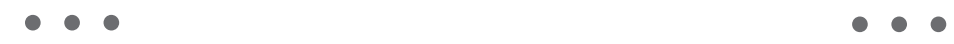


\section{Comparación de dos métodos de captura de Rhodnius prolixus (Hemiptera: reduviidae) en Attalea butyracea en Casanare, Colombia}

Néstor Pinto ${ }^{1}$, Germán Aguilera1 ${ }^{1}$, Felipe Guhl ${ }^{1}$, Mario Ortiz¹, Gustavo Vallejo², Lina Villa², Jairo Hernández³

Edwin Hincapié $^{3}$, Luis Castro ${ }^{4}$

${ }^{1}$ Centro de Investigaciones y en Microbiología y

Parasitología Tropical, Universidad de los Andes, Bogotá, D.C., Colombia

2 Laboratorio de Investigaciones en Parasitología Tropical, Universidad del Tolima, Ibagué, Colombia

${ }^{3}$ Unitrópico

4 Secretaría de Salud, Yopal, Casanare

Introducción. Los bosques de palma, en particular, de Attalea butyracea, presentan una amplia distribución geográfica en Colombia y constituyen un resguardo para los triatominos. Estas palmas se utilizan, principalmente, para cubrir las viviendas y para la producción de jugo y vino; dada su cercanía al hábitat humano pueden ser un riesgo para la población y, por consiguiente, es conveniente evaluar diferentes métodos de vigilancia para el control vectorial, especialmente en aquellas especies que se encuentran en el peridomicilio. El objetivo de este estudio fue comparar dos métodos para la búsqueda y captura de triatominos silvestres. Materiales y métodos. El estudio fue de tipo cuantitativo, descriptivo, se realizó en la vereda $\mathrm{El}$

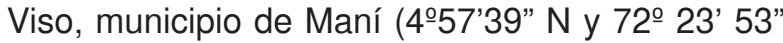
W) a una altura de $211 \mathrm{msnm}$. Se seleccionó al azar una muestra de 82 palmeras $A$. butyracea; en 21 de ellas se utilizó, primero, el método de búsqueda activa y, posteriormente, el método de jaula con gallina; en las 61 restantes se hizo al contrario. Las trampas se instalaron durante 12 horas a partir de las 17:00. Para el análisis de los datos se utilizó el programa SPSS®, versión 14.

Resultados. Se recolectaron 1.953 ejemplares de Rhodnius prolixus, con el método de búsqueda activa 222 (2 adultos y 220 ninfas); el índice de infestación fue de $48 \%$; el de colonización, de 35 $\%$, y la tasa de densidad, 2,7. Con el método de jaula se recolectaron 1.731 ejemplares (17 adultos y 1.714 ninfas); el índice de infestación fue de $98 \%$, el de colonización, de $48 \%$, y la tasa de densidad de 21,1.

Conclusiones. El método de la jaula con gallina fue más eficiente para la captura de $R$. prolixus en palmeras en estadio adulto y de ninfa, con diferencias estadísticamente significativas; este método, además, reduce el riesgo de infección del técnico al manipular los insectos.

\section{Identificación de fuentes alimentarias provenientes de humanos en Triatoma infestans (Hemiptera: Reduviidae) silvestre de Bolivia}

R. Buitrago, M. F. Bosseno, Renata Salas, E. Waleckx, F. Noireau, S. F. Brenière MIVEGEC, IRD, representación en Bolivia, La Paz, Bolivia

Laboratorio de Entomología Médica, Instituto Nacional de Laboratorios de Salud, La Paz, Bolivia

Introducción. Trypanosoma cruzi, agente causal de la enfermedad de Chagas transmitido por insectos vectores (Hemiptera: Reduviidae), mantiene ciclos silvestres y domésticos que pueden estar implicados por el movimiento de animales domésticos y silvestres infectados entre los ecótopos naturales y artificiales.

Para evaluar el contacto entre ambos ciclos y el riesgo que constituyen las poblaciones silvestres de vectores para la salud humana, hemos determinado el origen de las fuentes alimentarias de Triatoma infestans silvestre.

Materiales y métodos. De 2008 a 2010 se buscaron poblaciones silvestres de $T$. infestans alrededor del hábitat humano en la zona endémica para la enfermedad de Chagas de Bolivia, la cual comprende siete ecorregiones. La identificación del origen de las fuentes alimentarias se realizó después de la extracción del ADN por medio del ensayo de formación de cadenas heterodúplex del gen mitocondrial citocromo $\mathrm{B}$, combinado con secuenciación del gen y Blast en banco de genes. Resultados. Se han identificado varias fuentes alimentarias de humanos en poblaciones de $T$. infestans silvestres capturados en diferentes sitios, tanto en lugares cercanos al hábitat humano (30 m a 200 m) como más lejanos ( 800 m). En varios de estos lugares se ha evidenciado la existencia real del ciclo silvestre, por la identificación de una mayoría de fuentes alimentarias de animales silvestres.

Conclusiones. Los resultados apoyan la hipótesis según la cual el hombre se acerca ocasionalmente al hábitat de los triatominos silvestres, donde los vectores puede alimentarse de él, constituyéndose el hombre en un vínculo entre los ciclos doméstico y silvestre, con el riesgo de introducir cepas silvestres de T. cruzi al ciclo doméstico. 


\section{Desarrollo de un modelo de transmisión vectorial para el estudio de infecciones simples y mixtas de Trypanosoma cruzi}

P. G. Ragone', C. Pérez², A. M. Padilla ${ }^{3}$, M. M. Monje-

Rumi ${ }^{1}$, J. J. Lauthier ${ }^{1}$, A. M. Alberti-D'Amato ${ }^{1}$, N.

Tomasini ${ }^{1}$, M. Portelli ${ }^{4}$, R. O. Cimino ${ }^{4}$, M. A. Basombrío²,

P. Diosque ${ }^{1}$

1 Unidad de Epidemiología Molecular, Instituto de Patología Experimental, CONICET, Universidad Nacional de Salta, Argentina

2 Instituto de Patología Experimental, CONICET, Universidad Nacional de Salta, Argentina

3 Center for Tropical and Emerging Global Diseases, University of Georgia, Athens, GA, USA

${ }^{4}$ Cátedra de Química Biológica, Universidad Nacional de Salta, Argentina

Introducción. En la Provincia de Chaco encontramos que circulan cuatro linajes de Trypanosoma cruzi caracterizados genéticamente como Tcl, Tclll, TcV y TcVI. En el presente trabajo nos planteamos desarrollar un modelo de transmisión vectorial que nos permitiera mantener en el laboratorio, los parásitos aislados del campo, en un ciclo que simule su ciclo natural de infección. Nos propusimos, también, evaluar el comportamiento biológico de cuatro aislamientos en infecciones simples y en coinfección con otro aislamiento, a partir de infecciones mixtas experimentales.

Materiales y métodos. De un área geográfica restringida, endémica para la enfermedad de Chagas, seaislaron y caracterizarongenéticamente, parásitos representativos de los cuatro linajes. Éstos se mantuvieron realizando pasajes sucesivos entre insectos Triatoma infestans y ratones. Una vez establecido el ciclo, se realizaron tres experimentos consecutivos utilizando grupos de 5 ratones C57BL6J. En el primer experimento se determinó la dosis infectiva mínima común a los cuatro aislamientos. En el segundo experimento se estudió el comportamiento biológico de cada aislamiento por medio de la carga parasitaria en sangre periférica, respuesta serológica y daño histológico en corazón y cuádriceps crural. Finalmente, se estudiaron los mismos parámetros en infecciones producidas combinando dosis iguales de dos aislamientos diferentes.

Resultados. Se estandarizó una dosis infectiva mínima común de 10.000 parásitos por ratón. Los resultados mostraron diferencias significativas entre los cuatro aislamirntos para los parámetros de carga parasitaria en sangre periférica y daño histológico. Respecto a las infecciones mixtas, los estudios preliminares muestran una modificación en la carga parasitaria y en las lesiones producidas en corazón, de la mezcla de los linajes Tcl/TcVI, en comparación con la obtenida por los linajes individuales, y una modificación en la carga parasitaria de la mezcla Tclll/TcVI.

Conclusiones. En este trabajo pudimos establecer un modelo de transmisión vectorial que nos permitió estudiar el comportamiento de diferentes aislamientos en las infecciones.

\section{Fluctuaciones temporales y desplazamientos de Triatoma infestans silvestres a una escala microgeográfica}

Renata Salas, Rosio Buitrago, Philippe Brémond, Claudia Aliaga, François Noireau, Etienne Waleckx, Simone Frédérique Brenière

MIVEGEC, IRD, representación en Bolivia, La Paz, Bolivia

Laboratorio de Entomología Médica, Instituto Nacional de Laboratorios de Salud, La Paz, Bolivia

Introducción. Constantemente se descubren más y más poblaciones silvestres de Triatoma infestans pero su capacidad de colonización esta aún poco conocida. Su estudio en su hábitat natural es esencial para la comprensión de su biología, demografía y etiología. En un campo "semiantropizado" en una ladera de montaña (valle andino), se llevó a cabo un trampeo repetido de $T$. infestans durante un año utilizando el método de captura-marcado-recaptura, para evaluar los movimientos de los insectos.

Materiales y métodos. Al inicio del estudio se seleccionaron 50 sitios de captura. En 25 ensayos se dejaron durante una noche trampas con ratones como cebo. Al día siguiente se contaron los estadios de $T$. infestans capturados en cada trampa. Se marcaron como de tercer, cuarto y quinto estadio y adultos con esmaltes de colores específicos y se liberaron todos los insectos en su sitio de captura.

Resultados. A lo largo del estudio se capturaron o recapturaron $1.146 T$. infestans (trampas positivas: $22,2 \% ; 4,1 \pm 5,0$ insectos por trampa positiva), pero menos durante la temporada de lluvias; 17 sitios fueron negativos y 33 fueron positivos en 1 a 23 ensayos. Se marcaron 301 insectos y se registraron 138 recapturas, mayormente antes de 1 mes después de la marcación (60\%). Las recapturas de ninfas $(39,5 \%)$ fueron menores a las de adultos $(67,6 \%)$ y las de machos $(46,4 \%)$ menores a las de hembras (82,5\%). La mayoría de las recapturas correspondían a insectos marcados 
en el mismo sitio $(69,6 \%)$; para las otras, $19,6 \%$ de las recapturas de ninfas y $52,2 \%$ de los adultos correspondían a insectos que se desplazaron de un sitio a otro.

Conclusiones. Se mostró una cierta variación temporal de las poblaciones con algunos sitios de mayor densidad; se observó desplazamiento notable de ninfas y más movimientos de adultos hembra que machos a la escala microgeográfica; los machos podrían dispersarse más lejos y, entonces, ser menos veces recapturados en el espacio estudiado.

\section{Estudo molecular de espécies do gênero Rhodnius para a determinação de novos marcadores específicos}

Sueli Gardim¹, Cláudia Solano Rocha', Marco Túlio Alves da Silva ${ }^{2}$, Regina Maria Barretto Cicarelli ${ }^{1}$, João Aristeu da Rosa ${ }^{1}$

1 Departamento de Ciências Biológicas, Faculdade de Ciências Farmacêuticas de Araraquara, UNESP, São Paulo, Brasil

2 Instituto de Física, USP, São Carlos, São Paulo, Brasil

Introdução. A doença de Chagas tem como agente etiológico o protozoário Trypanosoma cruzi, cujos vetores pertencem à subfamília Triatominae. Os triatomíneos são insetos hematófagos pertencentes à ordem Hemiptera e família Reduviidae, que se distribuem predominantemente pela região neotropical, ondeepidemiologicamentesedestacam os gêneros Panstrongylus, Rhodnius e Triatoma. O gênero Rhodnius apresenta grande semelhança entre as suas espécies e algumas vezes apenas a avaliação de caracteres morfológicos não se faz suficiente para conferir dados para a correta identificação específica. Estudos moleculares se apresentam como uma alternativa bastante útil para auxiliar na identificação de espécies próximas e/ou crípticas. Nessa perspectiva este estudo visa contribuir para a identificação de $R$. neglectus, $R$. pictipes, $R$. prolixus e $R$. robustus, tendo como parâmetro os padrões de amplificação.

Materiais e métodos. $O$ fragmento mitocondrial Cyt $b$ foi amplificado e sequenciado em triplicata. As sequências consenso foram alinhadas e, com o intuito de obter um padrão de amplificação distinto para cada espécie, primers específicos foram desenhados considerando as regiões polimórficas. Os primers foram unidos em uma única reação de PCR (multiplex) e os resultados avaliados em gel de agarose.

Resultados. De acordo com os resultados, foi possível diferenciar as espécies propostas e os padrões encontrados foram os seguintes: $R$. prolixus, com quatro fragmentos de, aproximadamente, $380 \mathrm{pb}, 280 \mathrm{pb}$ (mais evidente), $250 \mathrm{pb}, 50 \mathrm{pb} ; R$. neglectus com dois fragmentos de, aproximadamente, 250pb (mais evidente) e $280 \mathrm{pb} ; R$. robustus com apenas um fragmento de $280 \mathrm{pb}$, e $R$. pictipes, com um fragmento com cerca de $250 \mathrm{pb}$.

Conclusão. A reação proposta mostrou-se bem sucedida para a diferenciação dessas quatro espécies de Rhodnius, e pode ser utilizada como ferramenta auxiliar às análises morfológicas na identificação de $R$. neglectus, $R$. pictipes, $R$. prolixus e $R$. robustus.

Auxílio: FAPESP

\section{Phylogenetic relationship among seven Triatoma species (Hemiptera, Reduviidae) from Brazil based on cytochrome $b$ and $16 S$ genes sequences}

Sueli Gardim¹, Cláudia Solano Rocha1', Marco Túlio Alves da Silva², Daniela Luz Ambrósio ${ }^{3}$, Regina Maria Barretto Cicarelli ${ }^{1}$, João Aristeu da Rosa ${ }^{1}$

1 Faculdade de Ciências Farmacêuticas, UNESP, Araraquara, São Paulo, Brasil

2 Instituto de Física, USP, São Carlos, São Paulo, Brasil

${ }^{3}$ University of Connecticut Health Center, Department of Genetics and Developmental Biology, Farmington, CT, USA

Introduction. The triatomines are vectors of the etiologic agent of Chagas' disease, Trypanosoma cruzi. The Triatoma genus is the largest and was divided in specific complexes according to morphological similarities and geographical distribution. The seven species studied can be found in the Central West region of Brazil, of which five belong to the oliverai subcomplex ( $T$. baratai, T. guazu, T. matogrossensis, T. vandae and $T$. williami) and $T$. costalimai and $T$. sordida belong respectively to infestans and sordida subcomplexes.

The aim of this study was to determine the phylogenetic relationship of these species, by analyses of cytochrome $b$ (Cytb) and 16S genes sequences of the mitochondrial DNA.

Material and methods. The specimens evaluated came from colonies of the Insectary of Triatominae, Faculdade de Ciências Farmacêuticas, UNESP, Brazil. After extraction of genomic DNA and amplification of Cytb and 16S genes fragments, they were sequenced. The sequences obtained together other sequences already available in 
GenBank were aligned using the Clustal W program, of BioEdit, and the phylogenetic inferences were conducted using the Bayesian analysis with the MrBayes 3.1.2 program. Sequences of the species Triatoma infestans, Panstrongylus megistus and Rhodnius neglectus were included as outgroup in the analysis to support the phylogeny.

Results. The species from Central West region were distributed in two clades and T. costalimai was pointed out these: the first clade compounded by $T$. sordida, T. matogrossensis and T. williami; and the second, by $T$. vandae, T. baratai and T. guazu.

Conclusion. The Cytb fragment showed a high degree of polymorphism and homoplasy and the phylogenetic analysis using the Cytb and 16S sequence while strengthening the relationships among the Central West region species show a division of the oliverai subcomplex.

Supported by CNPq and Fapesp

\section{High resolution melting del gen citocromo $B$, una poderosa herramienta para identificar fuentes alimenticias de vectores de la enfermedad de Chagas (Reduviidae: Triatominae)}

Víctor Hugo Peña, Geysson Javier Fernández, Omar Alfredo Cantillo, Andrés Mauricio Gómez, Ana María Mejía, Omar Triana

Grupo de Biología y Control de enfermedades Infecciosas, Instituto de Biología, Medellín, Colombia

Introducción. La dinámica de transmisión de Trypanosoma cruzies compleja ya que sus vectores se desplazan entre diferentes hábitats definiendo distintos ciclos de transmisión. La identificación de fuentes alimenticias de los insectos es esencial para identificar factores de riesgo, como focos de transmisión e incriminación de reservorios. En este trabajo presentamos una herramienta rápida y sensible para identificar fuentes alimenticias en triatominos, mediante el análisis High resolution melting (HRM) del gen citocromo $\mathrm{B}$.

Materiales y métodos. El perfil HRM de 14 especies fue obtenido mediante la amplificación del citocromo B por PCR en tiempo real. El perfil HRM a partir del contenido intestinal y heces de insectos alimentados sobre gallinas y humanos, y disecados a diferentes tiempos después de la alimentación, fue obtenido y comparado con el de las especies. Finalmente, se evaluó el perfil HRM de insectos alimentados con fuentes mixtas y de 20 insectos recolectados en el campo.
Resultados. El HRM de las 14 especies fue característico para cada una con altos porcentajes de confianza $(78,81 \%$ a 98,69 \%). Las especies con que fueron alimentados los insectos experimentalmente fueron identificadas hasta 30 días después de la alimentación. Además, las muestras obtenidas de alimentaciones mixtas mostraron los perfiles HRM de sus respectivas fuentes. En muestras de campo se encontró que los insectos recolectados en los domicilios estaban alimentados de perro y de humano, mientras los capturados en el peridomicilio y en hábitats silvestres mostraron perfiles HRM correspondientes a humanos, gallinas y zarigüeyas.

Conclusiones. El análisis HRM del gen citocromo B permitió la correcta identificación de fuentes alimenticias en insectos experimentalmente alimentados con una o varias fuentes hasta 30 días después de la alimentación. Además, esta técnica demostró ser útil en la identificación de las fuentes de alimentación de insectos recolectados en sus ambientes naturales. Por consiguiente, la técnica HRM es una poderosa herramienta para identificar fuentes alimenticias de vectores de la enfermedad de Chagas.

\section{Alta densidad y antropofilia de Triatoma dimidiata en una comunidad rural de Yucatán, México, pero baja transmisión de Trypanosoma cruzi}

Víctor Monteón, Irma Martínez, Jorge Hernández, César Alducín, Javier Balmes

Centro Investigaciones Biomédicas, Laboratorio Estatal, Campeche, México

Introducción. En la península de Yucatán, México, el único vector reconocido es Triatoma dimidiata el cual mantiene un ciclo peridoméstico y en épocas de calor aumenta de densidad poblacional en las viviendas rurales y con ello el riesgo de infección de $T$. cruzi. El objetivo fue determinar la antropofilia del vector, la infección por T. cruzi y datos electrocardiográficos.

Materiales y métodos. La población estudiada es de 411 habitantes. Participaron 57 voluntarios (47 mujeres y 10 hombres) se les tomó muestra de sangre para serología anti- $T$. cruzi, se les aplicó un cuestionario y un electrocardiograma. Se realizó la captura intradomicilio de triatomas con la ayuda de los propios pobladores. En los triatomas capturados se buscó T. cruzi por observación directa o por PCR y se identificó con marcadores de miniexón. Para preferencia alimenticia su usó PCR y heterodúplex. Para la serología se usó ELISA e IFI 
Resultados. El $50 \%$ de los voluntarios refieren haber sido picados por el triatoma y haber desarrollado reacción inflamatoria ("chinchoma"). El 3,5\% de ellos presentó serología positiva y ninguno de los positivos tuvo datos compatibles con enfermedad de Chagas. El $39 \%$ (17/44) de los triatomas capturados fueron positivos para $T$. cruzi y todos linaje I. El tipo de sangre encontrada fue $79 \%$ de humano, $36 \%$ de gallina y $31 \%$ de ratón.

Conclusiones. El riesgo de infección por T. cruzi en el humano es muy baja comparativamente con la alta antropofilia y porcentaje de infección que presenta $T$. dimidiata en esta región.

\section{- 0}

\section{Factores tripanolíticos de la hemolinfa de Rhodnius prolixus que actúan sobre Trypanosoma cruzi II, V y VI pero no sobre T. cruzi I, sugieren una transmisión selectiva de genotipos en Colombia, Venezuela y Centroamérica.}

Yazmín Suárez' ${ }^{1}$ Nohora Vega ${ }^{2}$, Daniel Zabala ${ }^{1}$, Yurani Granada1', Laura Roa'1, Xiomara Gaitán', Uriel Alvarado $^{1}$, Catalina Serrato ${ }^{1}$, Marleny Montilla ${ }^{3}$, Martha Texeira ${ }^{4}$, Daniel Urrea ${ }^{1}$, Lina Villa ${ }^{1}$, Julio Carranza ${ }^{1}$, Gustavo Vallejo ${ }^{1}$

1 Laboratorio de Investigaciones en Parasitología Tropical, Universidad del Tolima, Ibagué, Colombia

2 Laboratorio de Química de Proteínas, Universidad Nacional, Bogotá, D.C., Colombia

3 Instituto Nacional de Salud, Bogotá, D.C., Colombia

${ }^{4}$ Instituto de Ciencias Biomédicas, Universidad de São Paulo, São Paulo, Brasil

Introducción. Existe la hipótesis de que los vectores de la enfermedad de Chagas transmiten selectivamente ciertos genotipos de parásitos, determinando su distribución geográfica en América Latina.

Materiales y métodos. Para contrastar esta hipótesis, se evaluó el efecto de factores tripanolíticos de la hemolinfa de ninfas de $5^{\circ}$ estadio de $R$. prolixus sobre genotipos de $T$. cruzi. La hemolinfa se precipitó con sulfato de amonio al $30 \%$ y al $60 \%$, se dializó contra agua y PBS. El precipitado al $30 \%$, el sobrenadante y precipitado al $60 \%$ fueron incubados durante 10 horas con parásitos resuspendidos en medio LIT. Adicionalmente se evaluó el desarrollo de $T$. cruzi I y II en ninfas de 5 estadio de $R$. prolixus y $R$. colombiensis alimentadas con sangre de ratones infectados con T. cruzi l y T. cruzill.

Resultados. Se observó actividad lítica en la hemolinfa de R. prolixus contra los genotipos II, V y VI, aglutinación contra el genotipo IV y ninguna actividad sobre los genotipos I y III. Al evaluar las fracciones se confirmó un porcentaje de actividad lítica de $80,7 \%, 71,9 \%$ y $87 \%$ en el precipitado al $60 \%$ contra los genotipos II, V y VI de $T$. cruzi respectivamente. Estos resultados estarían correlacionados con el desarrollo del parásito en el intestino del vector, ya que se presentó una menor proporción de formas amastigotes, esferomastigotes, epimastigotes y tripomastigotes para $T$. cruzi II que para $T$. cruzi I en la ampolla rectal de $R$. prolixus y $R$. colombiensis. La mayor asociación de $R$. prolixus y $R$. colombiensis con $T$. cruzi I explicaría la predominancia de este genotipo en Colombia

Conclusión. Los factores inmunes de $R$. prolixus ejercen un papel determinante en la transmisión selectiva de genotipos de T. cruzi, favoreciendo la predominancia de T. cruzil en Colombia, Venezuela y los países centroamericanos.

\section{Bandeo $\mathrm{C}$ en cromosomas de Triatoma} infestans del sur de Perú

Yenny del Rosario Guevara-Venegas, Olga

Bracamonte-Guevara, Misael Guevara-Paredes Laboratorio de Citogenética, Facultad de Ciencias

Biológicas, Universidad Nacional Mayor de San Marcos, Lima, Perú

Introducción. Las poblaciones de Triatoma infestans en las localidades de Santa Rita de Siguas y Nazca, pertenecen a la principal región chagásica al sur de Perú.

En los cromosomas de esta especie existen regiones heterocromáticas en los autosomas que presentan patrones de bandas " $C$ " relacionadas con su localización, tamaño y que pueden servir de patrones de diferenciación de poblaciones de $T$. infestans. La distribución de los bloques heterocromáticos que presentan a permitido clasificarlos como de tipo $A, B$ y $C$, con variantes $A_{1}, A_{2}, A_{3}, B_{1}, B_{2}, B_{3}$.

En vista de la importancia epidemiológica de este agente vector, el conocimiento de las características cromosómicas de $T$. infestans, resulta interesante, pudiendo determinar su expresión, mecanismo de herencia e identificar el componente genético asociado a la resistencia a piretroides.

El objetivo del trabajo fue determinar mediante la aplicación de la técnica de bandeo $\mathrm{C}$, la ubicación de las regiones heterocromáticas en los cromosomas de $T$. infestans para identificarlas en las muestras poblacionales de Santa Rita de Siguas y Nazca. Determinar la presencia de polimorfismos 
en poblaciones y entre poblaciones en los pares cromosómicos y, establecer una base de datos de características citogenéticas para ambas.

Materiales y métodos. Tejido de gónadas de individuos machos de la población de Nazca (7) y Santa Rita de Siguas (7). Se aplicó la técnica de coloración del bandeo "C" (Summers, 1972) modificado por Panzera (1992).

Resultados. Presencia de patrones de distribución de bandas intersticiales en los cromosomas autosómicos de tipo $A$, B y $C$ con variantes $A_{1}$, $A_{2}, A_{3}, B_{1}, B_{2}$ y $B_{3}$, en los cromosomas de ambas muestras poblacionales de Santa Rita de Siguas y Nazca.

Conclusiones. Presencia de polimorfismos cromosómicos en ambas muestras poblacionales, en cantidad y localización de las regiones heterocromáticas en poblaciones y entre poblaciones. 